\title{
Granito Terra Nova - petrologia e geocronologia: um granito tipo-A da Província Aurífera Alta Floresta — Cráton Amazônico
}

\author{
Terra Nova Granite - petrology and geochronology: an A-type \\ granite of Alta Floresta Gold Province - Amazonian Craton
}

\author{
Ezenildes Silva Prado, Márcia Aparecida de Sant'Ana Barros*, \\ Francisco Egídio de Cavalcante Pinho, Ronaldo Pierosan
}

\begin{abstract}
RESUMO: O Granito Terra Nova faz parte da Suíte Intrusiva Teles Pires e se localiza em torno do município homônimo, na Província Aurífera Alta Floresta. $\mathrm{O}$ granito em questáo ocorre em forma de um batólito alongado de direção NE-SW, cujas rochas são de coloraçáo róseo-avermelhado a vermelho-tijolo com granulação média a grossa, homogêneas, mostrando localizadamente enclaves máficos microgranulares e cavidades miarolíticas preenchidas com fluorita, quartzo e sulfetos. Microscopicamente, as rochas estudadas mostram texturas xenomórfica a hipidiomórfica inequigranular, sendo comum o intercrescimento pertítico e gráfico. Os minerais essenciais que compóem a rocha são feldspato alcalino pertítico e quartzo com proporçôes inferiores de plagioclásio, biotita e minerais acessórios. Estimativas da composição modal permitem plotar as amostras no campo dos álcali-granitos com variaçáo para o campo de sienogranito. $\mathrm{O}$ resultado das análises químicas para elementos maiores e traços feitas em 17 amostras, indicaram natureza sub-alcalina, caráter metaluminoso a levemente peraluminoso e padrão de elementos terras raras com suave enriquecimento de leves sobre pesados e anomalia de Eu negativa de moderada a forte. Diagramas multielementares mostram enriquecimento de $\mathrm{Rb}$ e Th e anomalias negativas de $\mathrm{Ba}, \mathrm{Nb}, \mathrm{Ta}, \mathrm{Sr}, \mathrm{P}$ and Ti. As temperaturas do magma parental foram estimadas entre 748 a $855^{\circ} \mathrm{C}$. Os dados de campo, a composição mineralógica e o comportamento geoquímico das rochas são coerentes com um ambiente tectônico do tipo anorogênico ou pós-colisional para o granito em questão. O quimismo do Granito Terra Nova permite ainda classificá-lo como um granito rapakivi do tipo $\mathrm{A}$, oxidado. Dados $\mathrm{U}-\mathrm{Pb}$ em zircáo resultaram em uma idade de cristalizaçáo $1727 \pm 42 \mathrm{Ma}$ e $\varepsilon_{\mathrm{Nd}}$ com valores entre $+1,07$ e $-0,98$ para a idade modelo $\mathrm{Nd}$ de 2,0 a 2,17 Ga.
\end{abstract}

PALAVRAS-CHAVE: Teles Pires; tipo A; Alta Floresta; geoquímica.

\begin{abstract}
The Terra Nova granite is part of Teles Pires Intrusive Suite and is located near of homonymous municipality, in Alta Floresta Gold Province (AFGP). The studied granite occurs as NE-SW elongated batholiths, which rocks are reddish-pink to brick-red with medium to coarse granulation, homogeneous, showing localized microgranular mafic enclaves and miarolitic cavities filled with fluorite, quartz and sulphides. Under microscope, the studied rocks show inequigranular xenomorphic to hypidiomorphic textures with common perthites and graphic intergrowing. Essential minerals that compound the rock are perthitic alkali feldspar and quartz with minor plagioclase, biotite and accessory minerals. Visual estimation of modal composition allows plotting the samples within the alkali granite field varying to the syenogranite field. Chemical analysis results for major and trace elements of 17 samples indicate a subalkalic nature, metaluminous to slightly peraluminous and a rare earth elements pattern with slight LREE enrichment over HREE and strong to moderate Eu negative anomaly. Multielement diagrams show Rb and Th enrichment and $B a, N b$, $\mathrm{Ta}, \mathrm{Sr}, \mathrm{P}$ and Ti negative anomalies. The parental magma temperature was estimated between 748 and $855^{\circ} \mathrm{C}$. Field data, mineralogical composition and geochemical behavior are coherent with a post-collisional to anorogenic setting for the granite emplacement. The chemistry of Terra Nova granite allows classifies it as oxidized A-type rapakivi granite. U-Pb zircon data resulted in a crystallization age of $1727 \pm 42 \mathrm{Ma}$ and $\varepsilon_{N d}$ values between +1.07 and -0.98 for $\mathrm{Nd}$ model age from 2.0 to $2.17 \mathrm{Ga}$.
\end{abstract}

KEYWORDS: Teles Pires; A-type; Alta Floresta; geochemistry.

Universidade Federal de Mato Grosso - UFMT, Cuiabá (MT),Brasil.E-mail:ezenildesster@gmail.com,mapabarros@yahoo.com,aguapei@yahoo.com, ronaldo.pierosan@yahoo.com.br

*Autor correspondente

Manuscrito ID 27090. Recebido em: 22/05/2012. Aprovado em: 24/10/2012 


\section{INTRODUÇÃO}

Granitos com características petrográficas e geoquímicas do tipo-A, pós-colisionais a anorogênicos são comuns em todo o Cráton Amazônico e variam em idade desde $2763 \pm 7 \mathrm{Ma}$ (Barros et al. 2004) até $974 \pm 6 \mathrm{Ma}$ (Bettencourt et al. 1999). O Granito Terra Nova consiste de um maciço batolítico aflorante nas proximidades do município de Terra Nova do Norte, Mato Grosso (Fig. 1). Esse maciço está relacionado à Suíte Teles Pires desde a definição da unidade por Silva et al. (1974), sendo que suas ocorrências são consideradas por alguns autores (Moreton \& Martins 2005) como seção-tipo da unidade. Publicaçóes referentes a esta ocorrência se concentraram preferencialmente em trabalhos de cunho regional (Silva et al. 1980, Moreton \& Martins 2005, Lacerda Filho 2004). Associado a esse batólito, nas proximidades do município de Nova Santa Helena ocorre um corpo de menor dimensão.

O termo "Teles Pires" - Granito Teles Pires, Suíte Teles Pires, Suíte Intrusiva Teles Pires, Suíte vulcano-plutônica Teles Pires - vem sendo atribuído a uma série de granitoides, algumas vezes associados a rochas vulcânicas, que ocorrem no norte do estado de Mato Grosso. Essas ocorrências estão distribuídas entre as bacias paleozoicas do Parecis (a sul) e Alto Tapajós (ao norte) e estão preferencialmente inseridas na Província Aurífera Alta Floresta (PAAF).

Estudos petrogenéticos apontam para uma ampla diversidade composicional em granitoides e vulcânicas correlacionados ao evento Teles Pires. A afinidade litoquímica tem sido genericamente definida como cálcio-alcalino alto -K (Moreton \& Martins 2005) ou compatível com granitos tipo-I altamente fracionados com similaridade com granitos alcalinos tipo-A (Lacerda Filho 2004). Barros et al. (2009) apresentam dados geoquímicos para as ocorrências vulcano-plutônicas na porção norte da PAAF na região de Moriru, que indicam afinidade compatível com magmatismo tipo-A aluminoso. Alves et al. (2010) propóem um magmatismo tipo-A de tendência peralcalina para as ocorrências a leste do Granito Terra Nova. De modo semelhante ao que vem ocorrendo com as características litoquímicas, os resultados isotópicos têm indicado idades $\mathrm{U}-\mathrm{Pb}$ variando desde $1801 \pm 11 \mathrm{Ma}$ até $1757 \pm 16 \mathrm{Ma}$ (Pinho et al. 2003, Silva \& Abram 2008, Santos et al. 2000, Moreton \& Martins 2005), idades modelo $\mathrm{T}_{\mathrm{DM}}$ de 2,21 a 2,11 Ga e valores de $\varepsilon_{\mathrm{Nd}}$ de $-3,4$ a 1,6 (Pinho et al. 2003, Santos et al. 2000, Moreton \& Martins 2005).

As interpretaçóes quanto ao ambiente geotectônico sugerem a vinculação com um evento anorogênico (Silva et al. 1974) ou com os estágios pós-colisionais/pós-orogênicos em relação ao orógeno que originou a granitogênese da PAAF (Pinho et al. 2003, Lacerda Filho 2004, Silva \& Abram
2008, Alves et al. 2010). Os granitoides e vulcânicas caracterizadas por Pinho et al. (2003) e Barros et al. (2009) vêm sendo correlacionados por Lacerda Filho (2004) ao Granito São Romão e às vulcânicas ao Grupo Colíder, respectivamente. Dessa forma, destaca-se a importância de uma melhor caracterização da Suíte Teles Pires e a relação entre as ocorrências das regióes de Terra Nova do Norte, Peixoto de Azevedo e do extremo norte do estado. O presente trabalho visa a contribuir com o entendimento da geologia do Granito Terra Nova, bem como da evolução geotectônica dessa porção do Cráton Amazônico.

\section{MÉTODOS ANALÍTICOS}

As etapas de campo para mapeamento litológico do maciço granítico e coleta de amostras para estudos petrográficos e análises geoquímicas foram planejadas com base no Mapa Geológico da PAAF (Frasca et al. 2004) e no Mapa Geológico do Estado de Mato Grosso, escala 1:1.000.000 (Lacerda Filho 2004). Os dados cartográficos foram compilados de imagens obtidas a partir do Google Earth. E realizaram-se três etapas de campo para mapeamento e coleta de material, totalizando cerca de 70 amostras. Além do Granito Terra Nova, foi estudada uma ocorrência próxima da cidade de Nova Santa Helena, relacionada à Suíte Teles Pires. No total, foram descritos 28 pontos de mapeamento, nos quais se coletaram 17 amostras de rochas representativas para a confecção de análise petrográfica, litoquímica e geoquímica isotópica. As seçôes delgadas foram confeccionadas no laboratório de laminação do Departamento de Recursos Minerais da Universidade Federal do Mato Grosso (DRM/UFMT). O estudo petrográfico visou à caracterização litológica do granito e fundamentou a seleção de amostras para as análises geoquímicas. Para a descrição petrográfica e aquisição de fotomicrografias utilizou-se o microscópio petrográfico BX 41 (Olympus).

As análises litoquímicas foram realizadas em laboratório comercial (Acmelabs) no Canadá. Analisaram-se os elementos segundo metodologias relacionadas à Inductively Coupled Plasma-Emission Spectrometry (ICP-ES; elementos maiores) e Inductively Coupled Plasma - Mass Spectrometry (ICP-MS; elementos traços). O processamento dos dados litoquímicos foi realizado com o programa GCDkit 2.3 (Janousek et al. 2006) e o tratamento, posteriormente, em programas gráficos. Já o cálculo de temperatura contou com o método de saturação de zircão de Watson \& Harrison (1983), baseado em elementos maiores e $\mathrm{Zr}$.

Os dados geocronológicos foram obtidos segundo o método U-Pb em zircão em uma amostra representativa do granito (EPR-24). A separação dos grãos de zircão 


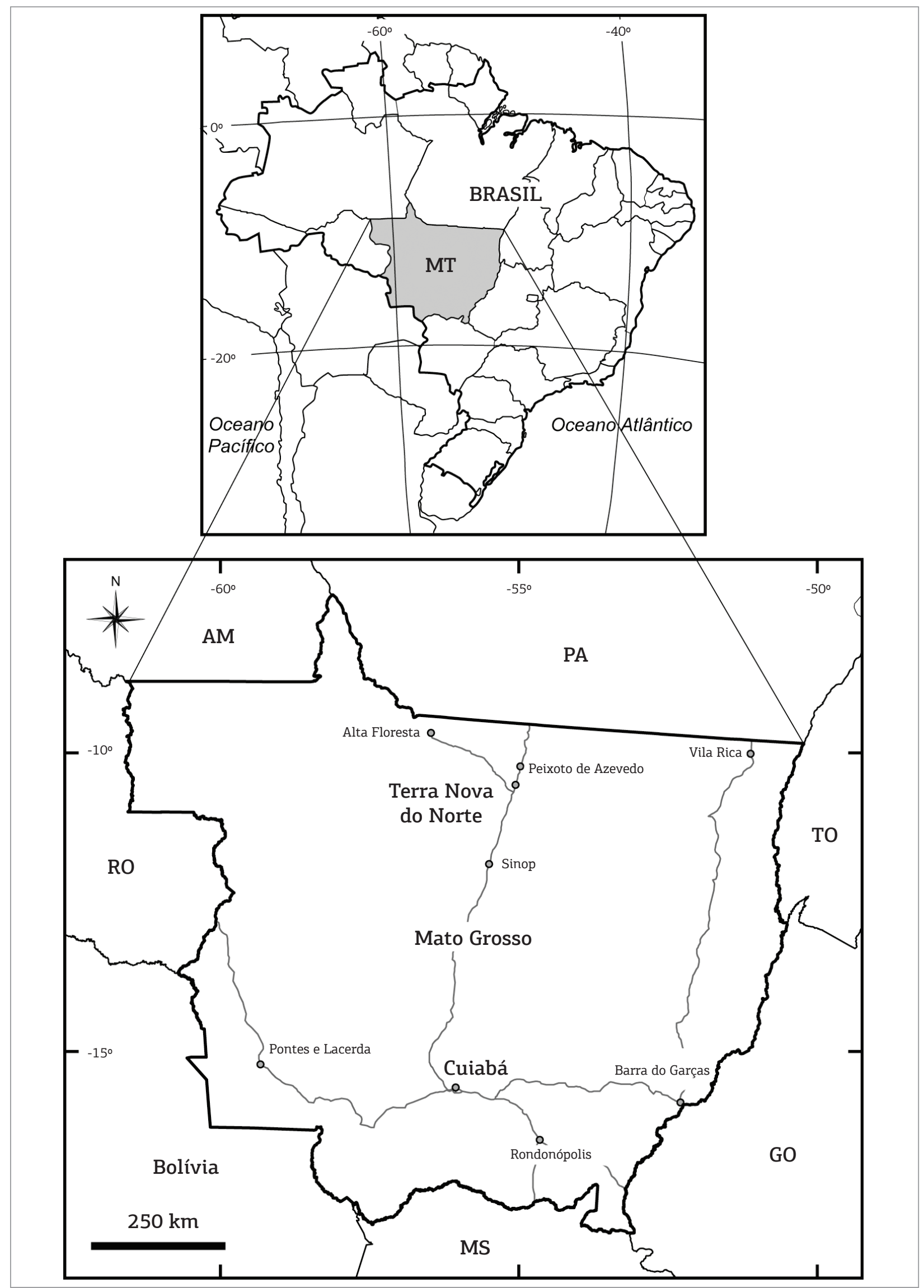

Figura 1. Mapa de localização e vias de acesso. 
foi realizada nos laboratórios da UFMT e seguiram metodologias convencionais de cominuição de rocha e concentração gravimétrica e magnética de minerais pesados e não magnéticos. As análises aconteceram no Laboratório de Geocronologia da Universidade de Brasília (UnB) por Inductively Coupled Plasma - Mass Spectrometry - Laser Ablation (ICP-MS-LA) com equipamento do tipo Laser Ablation Multicolector - ICP-MS (Neptune).

Os dados isotópicos $\mathrm{Sm}-\mathrm{Nd}$ em rocha total foram obtidos em quatro amostras representativas do Granito Terra Nova (EPR-33, EPR-60, EPR-63 e EPR-69). Por sua vez estas foram cominuídas e pulverizadas segundo técnicas convencionais no laboratório da Universidade Federal do Rio Grande do Sul (UFRGS), mesmo local no qual foram feitas análises de Geologia Isotópica. Uma solução de ${ }^{150} \mathrm{Nd}-{ }^{149} \mathrm{Sm}$ foi adicionada às amostras antes da dissolução com ácido fluorídrico e nítrico na proporção de 5:1 em cápsulas de Savilax ${ }^{\circledR}$. Após a dissolução e evaporação, estas foram dissolvidas com $7 \mathrm{~mL}$ de HCL $6 \mathrm{~N}$ e, posteriormente, com HCL
2,5 N. O Nd e Sm foram extraídos usando procedimentos convencionais de força iônica descritos em Patchett \& Ruiz (1987) e analisados no espectrômetro de massa Finningan MAT-262 com 7 coletores. Valores de $\varepsilon_{\mathrm{Nd}}$ foram calculados tomando como base a idade U-Pb obtida para a amostra de granito EPR 24. As idades modelos $\left(\mathrm{T}_{\mathrm{DM}}\right)$ foram calculadas seguindo modelo de De Paolo (1981).

\section{CONTEXTO GEOLÓGICO-GEOTECTÔNICO}

O Granito Terra Nova está geograficamente inserido na PAAF, de Dardene \& Schobbenhaus (2001), na região limítrofe entre as províncias geotectônicas Tapajós-Parima $(2,03$ - 1,88 Ga) e Rondônia-Juruena (1,82 - 1,52 Ga) de Santos et al. (2000), e as províncias Ventuari-Tapajós $(1,9$ - 1,8 Ga) e Rio Negro-Juruena $(1,8$ - 1,55 Ga) de Tassinari \& Macambira (1999) (Fig. 2).

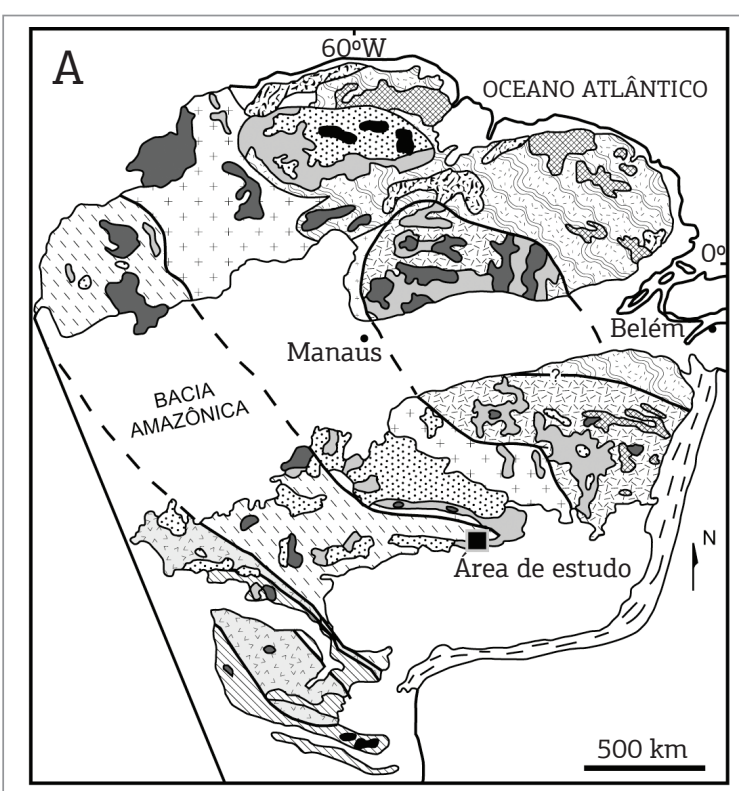

LEGENDA

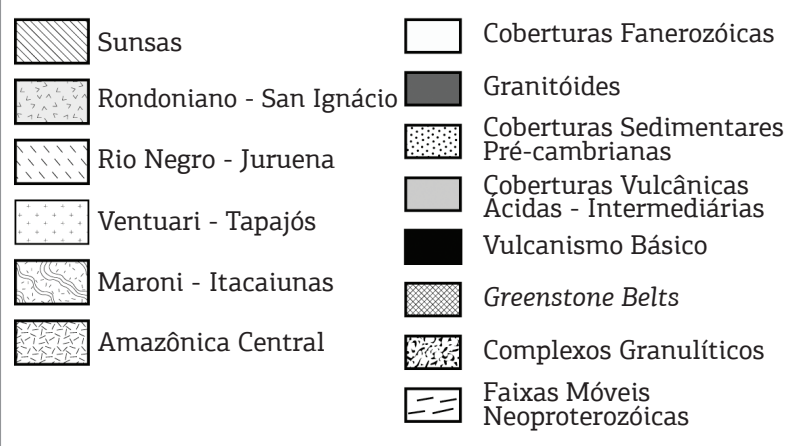

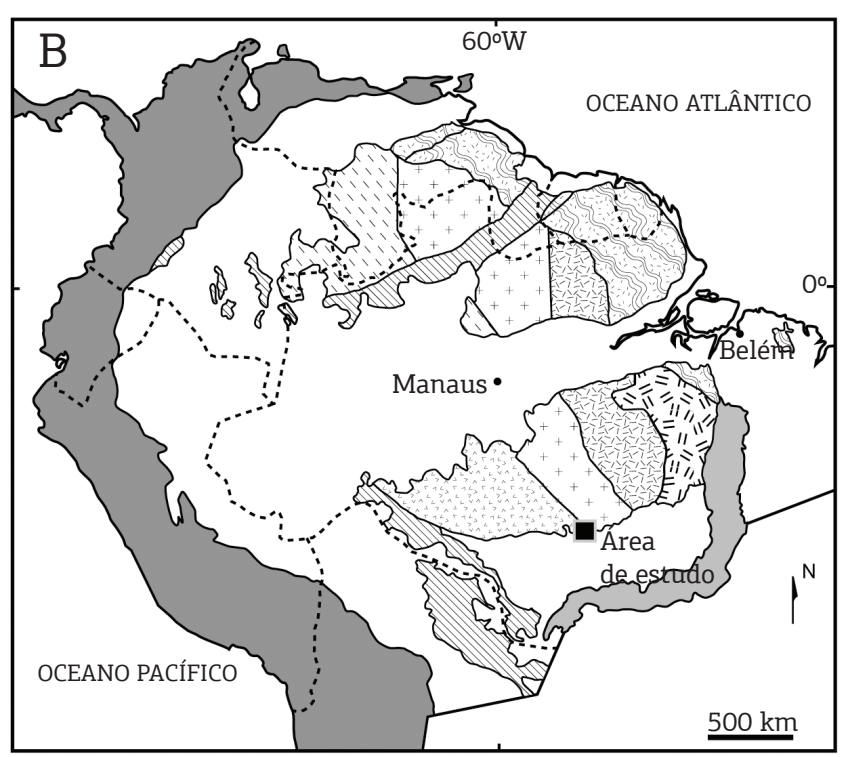

LEGENDA

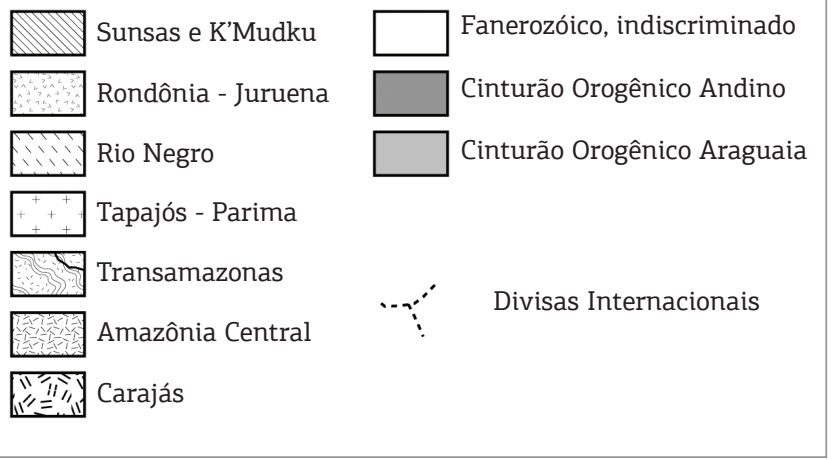

Figura 2. Mapa de distribuição das províncias geocronológicas do Cráton Amazônico segundo (A) Tassinari \& Macambira 2004, e (B) Santos et al. 2006. 
A PAAF é constituída por granitoides que hospedam mineralizaçôes auríferas, configurando uma área alongada de direção NW-SE limitada a norte pelo gráben do Cachimbo e a sul pelo gráben dos Caiabis (Fig. 3). Em termos geotectônicos, Lacerda Filho (2004) agrupam os granitoides da PAAF no Domínio Juruena, da Província Rondônia-Juruena e relacionam sua origem ao Arco Magmático Juruena com idades entre 1,85 e 1,75 Ga. Segundo esse modelo, o Arco Magmático Juruena é dividido em dois domínios: a norte um terreno plutono-vulcânico deformado e com idades entre 1,85-1,75 Ga, e a sul um terreno granito-gnássico de médio a alto grau metamórfico com idades entre 1,78 - 1,75 Ga. Nesse contexto, o magmatismo Teles Pires é compreendido como granitoide pós-orogênico em relação à orogênese do Arco Magmático Juruena.

\section{Geologia regional}

O Granito Teles Pires foi definido inicialmente por Silva et al. (1974, 1980), que o descreveram como batólitos e stocks circulares em mapa, subvulcânicos, apresentando tendência alasquítica e com homogeneidade nas texturas petrográficas. Estas rochas são frequentemente de cor avermelhada, de granulação fina a grossa, equigranulares a porfiríticas, granofíricas e leucocráticas (biotita < 3\%). Sua composição modal está entre o álcali-feldspato granito e sienogranito e, mais raramente, monzogranito.

Assinaturas geofísicas reportadas por Moura (2004), combinadas com observaçóes de campo e dados petrográficos e químicos, permitiram individualizar na regiāo de Peixoto de Azevedo - Novo Mundo (norte de MT) três tipos de granitos Teles Pires, classificados como TP1, TP2 e TP3.

O TP1 é descrito como constituído por rochas equigranulares, e apresenta matriz de granulação média a grossa, cor rósea a branco e composição modal de álcali- feldspato granito a sienogranito com monzogranito subordinado, enquanto o TP2 é representado por corpos de álcali-granito com granulação fina e coloração bem avermelhada, que apresentam textura porfirítica, com fenocristais de feldspato potássico, quartzo bipiramidado, anfibólio sódico de hábito tabular e encraves máficos microgranulares. E o TP3 constitui-se por corpos de composição eminentemente sienogranítica com textura equigranular fina a média, cores róseas e concentraçóes de máficos inferiores a 5\%. Nesta

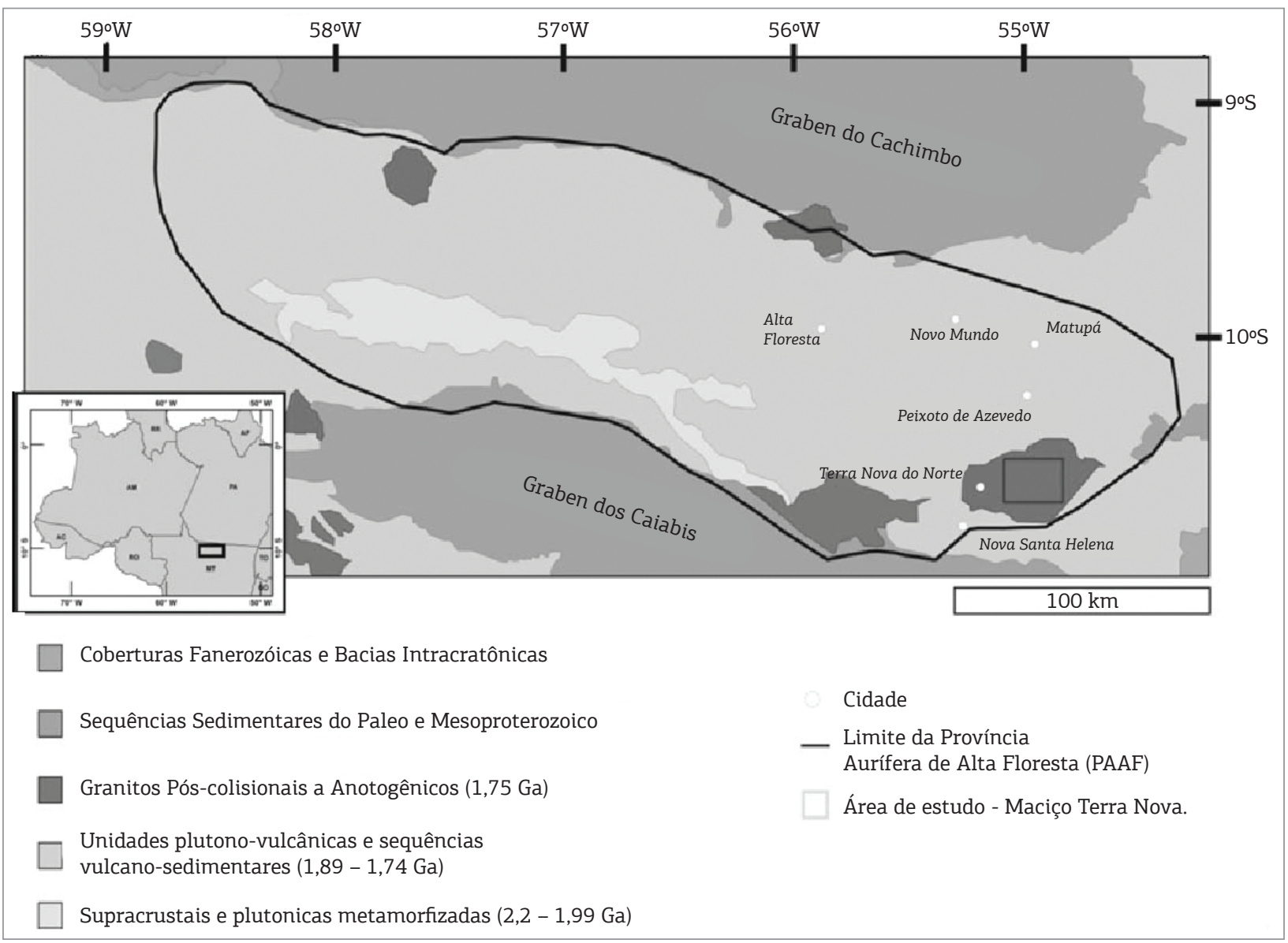

Figura 3. Mapa de localização da área de estudo apresentando a Província Aurífera Alta Floresta (compilado e modificado de Paes de Barros, 2007). 
classificação, o TP1 é o que mais se assemelha aos granitos Teles Pires, de Silva et al. (1980).

\section{Geologia do Granito Terra Nova}

O Granito Terra Nova corta as suítes intrusivas Matupá - Fácies 2 e 4 e as vulcânicas Colider e está recoberto por sedimentos quaternários (Fig. 4). Este maciço é constituído por um conjunto de corpos graníticos porfiríticos, granulação média a grossa, coloração róseo-avermelhada a vermelha escura, sendo composto basicamente por quartzo, feldspato potássico, plagioclásio e biotita. Fluorita, muscovita, apatita e zircão ocorrem como

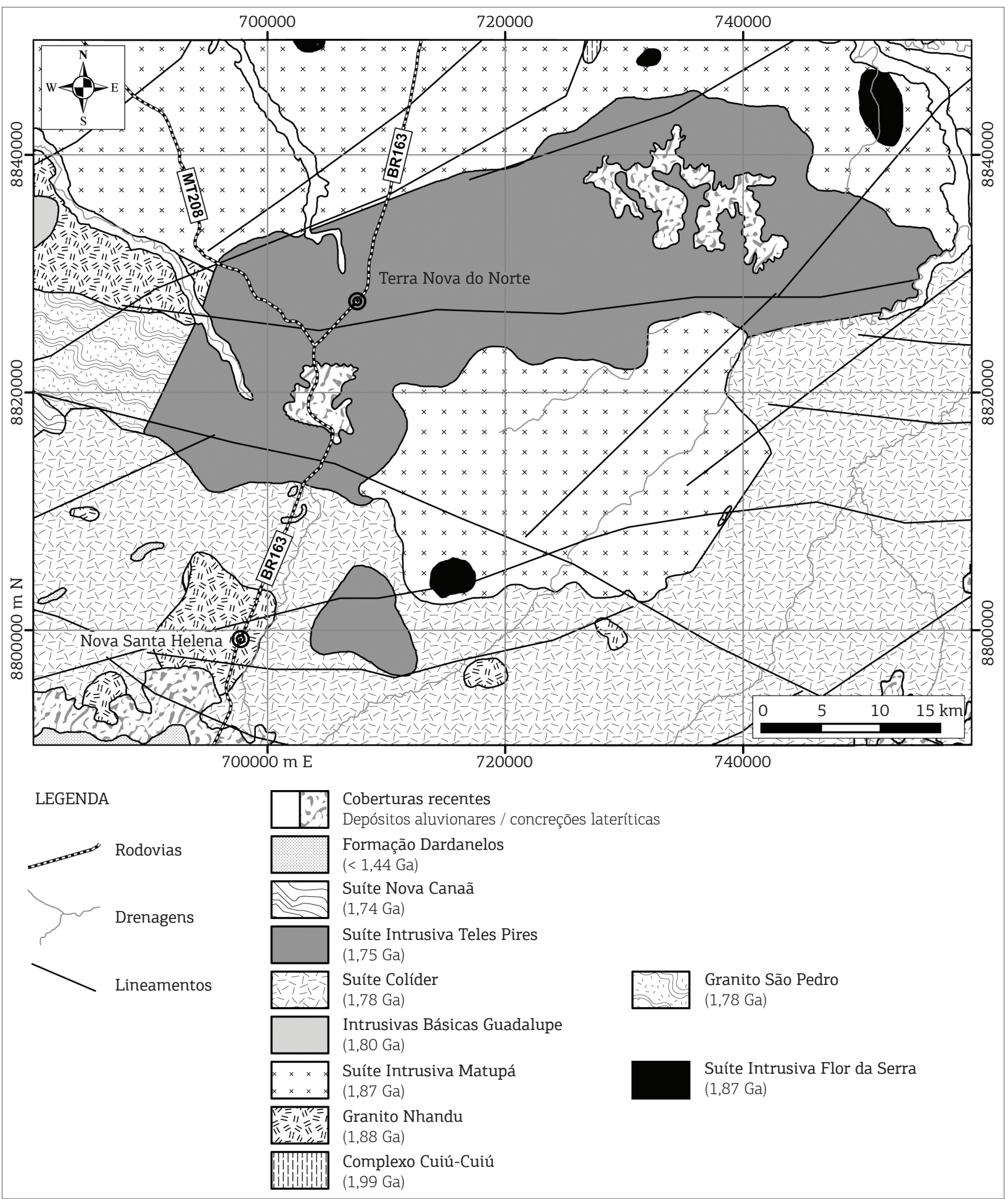

Figura 4. Mapa geológico da área do Granito Terra Nova (adaptado de Souza et al. 2005, Silva \& Abram 2008). 
minerais acessórios. Mostra caráter isotrópico com cristais irregulares, textura rapakivi e se distribui na forma de morros alongados com blocos in situ ou rolados (Figs. 5A e B). Não conta com deformaçóes e/ou metamorfismo e mostra capas de alteraçôes intempéricas. Os blocos são fragmentos rochosos arredondados, associados a grãos grossos de quartzo e feldspato desagregados que formam uma cobertura típica nas áreas de ocorrência desta unidade. As superfícies de cobertura sobre o granito são aplainadas e constituídas dominantemente por solos argilo-arenosos de tonalidade avermelhada, ricos em concreções ferruginosas. Nas partes mais baixas, encontra-se coberto por solos amarelos e areias brancas, além de colúvios e alúvios.

$\mathrm{Na}$ região de Nova Santa Helena foi identificado um corpo granítico com características petrográficas similares às do Granito Terra Nova, destacando-se pela presença de enclaves máficos microgranulares, indicadores de mistura heterogênea de magmas, e também pela presença de cavidades miarolíticas preenchidas por fluorita, quartzo e sulfetos (Figs. 5C e D).

\section{Petrografia}

O granito Teles Pires da regiáo de Terra Nova do Norte e Nova Santa Helena se caracteriza como feldspato alcalino granito a sienogranito, com textura equigranular média a grossa e conteúdos de biotita inferiores a 5\%. Localizadamente são observados termos granofíricos variando de porfirítico, com fenocristais de plagioclásio e feldspato alcalino em matriz fina a média, até rochas equigranulares finas com abundante intercrescimento micrográfico.
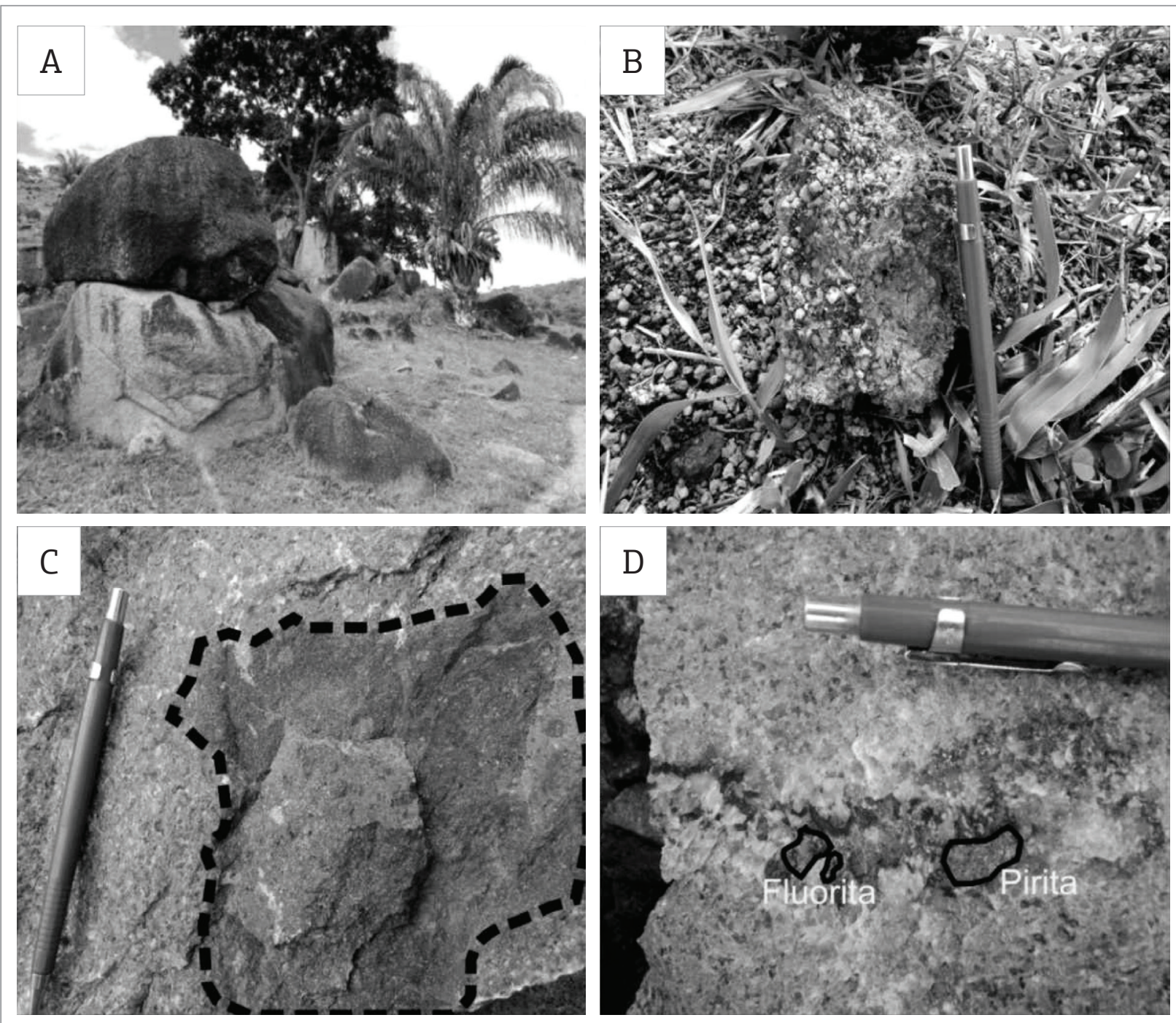

Figura 5. (A) Formas de ocorrência do Granito Terra Nova, com blocos e matacões; (B) Aspecto do granito com granulação média a grossa, coloração róseo-avermelhado a vermelho-tijolo; $(C)$ Enclaves máficos microgranulares caracterizados pela inclusão de cristais de feldspato alcalino em meio ao magma máfico; (D) Cavidades miarolíticas preenchidas por fluorita, quartzo e sulfetos. 
Nas rochas equigranulares médias a grossas, o feldspato alcalino dominante é o ortoclásio, que invariavelmente é pertítico com lamelas de albita, desenvolvendo maclas polissintéticas, com microclínio subordinado (Fig. 6B). Os cristais possuem formas subédricas a anédricas, com dimensóes variando de 1 a $5 \mathrm{~mm}$. O quartzo ocorre sob formas anédricas, caracterizando-se como um mineral tardio (Fig. 6A). O plagioclásio possui dimensões de 0,5 a $3 \mathrm{~mm}$ e se apresenta como prismas subédricos, parcialmente sericitizados e ocasionalmente inclusos em feldspato alcalino tardio (Fig. 6C). A biotita ocorre como cristais subédricos a anédricos (1 a $2 \mathrm{~mm}$ ), geralmente cloritizada (Fig. 6C). Raramente se observa muscovita euédrica associada a biotita e/ou inclusa em quartzo tardio. Essa feição pode indicar supersaturação em alumina nos líquidos mais tardios. Como minerais acessórios, ocorrem óxidos de Fe-Ti, titanita, zircão e apatita euédricos a subédricos. Clorita, mica branca e epidoto dominam como minerais de alteração hidrotermal.
Os granófiros porfiríticos se diferenciam dos termos equigranulares essencialmente por apresentarem textura inequigranular caracterizada por fenocristais de plagioclásio (de até $8 \mathrm{~mm}$ ) e feldspato alcalino (de até $6 \mathrm{~mm}$ ) e um menor conteúdo de biotita. Os termos equigranulares finos são constituídos dominantemente por feldspato alcalino e quartzo em extenso intercrescimento micrográfico (Fig. 6D), com biotita e muscovita de forma localizada.

\section{Geoquímica}

Os dados geoquímicos são apresentados na Tab. 1 . As amostras analisadas são álcali-granitos a sienogranitos, com altos teores de $\mathrm{SiO}_{2}$ variando de 70 a $77 \%$, com exceção da amostra EPR-33, que apresenta conteúdos de $\mathrm{SiO}_{2}$ mais baixo $(68,91 \%)$.

A aplicação de diagramas binários de variação proposto por Harker (1909) (Fig. 7), usando $\mathrm{SiO}_{2}$ como índice de diferenciação contraposto com os elementos maiores, sugere uma sequência de evolução magmática contínua, com
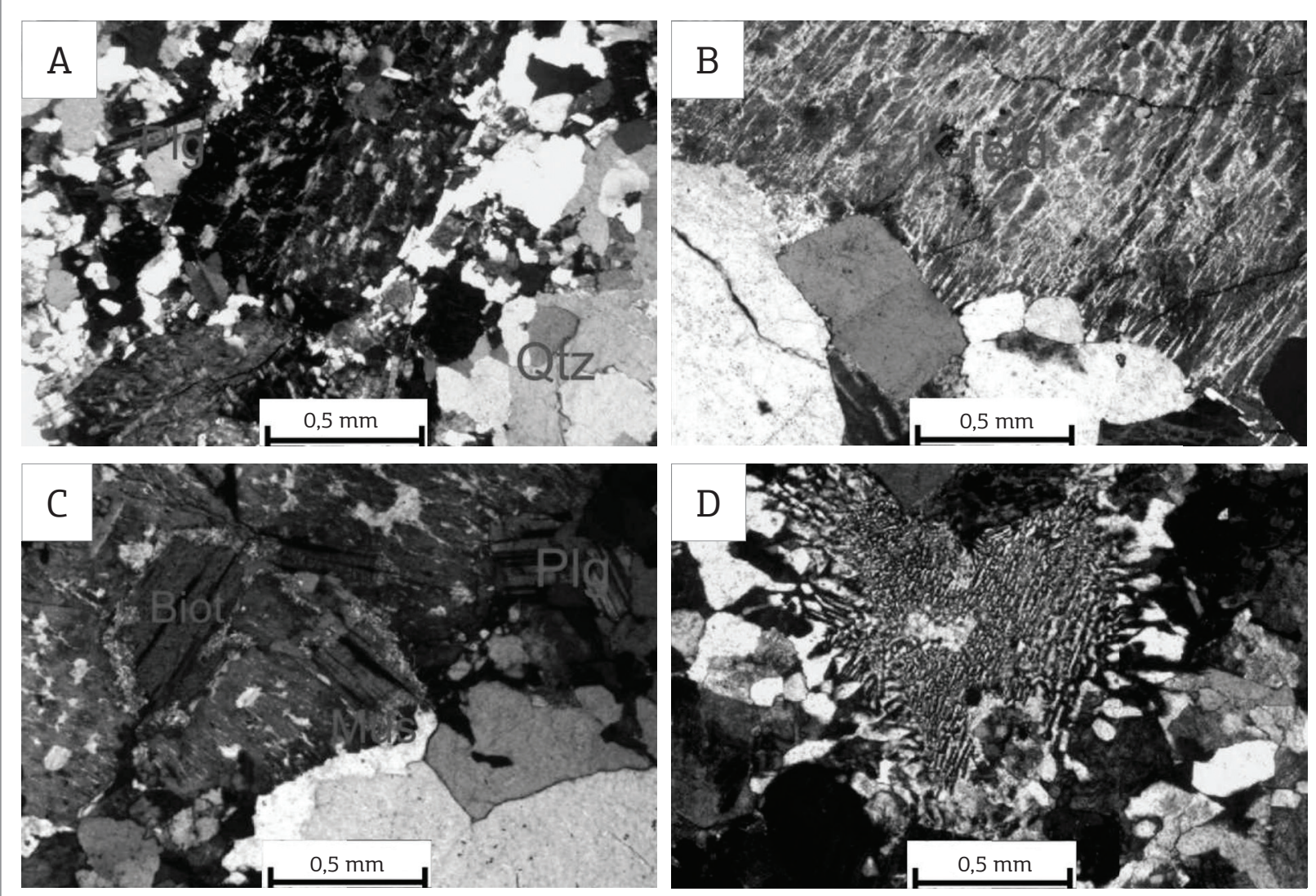

Figura 6. Fotomicrografias do Granito Terra Nova: (A) feldspato alcalino subédrico, com intercrescimento pertítico, associado a quartzo; (B) feldspato alcalino subédrico e anédrico intersticial associado a quartzo; (C) biotita subédrica associada a plagioclásio e feldspato alcalino pertítico subédricos, e quartzo intersticial; (D) intercrescimento micrográfico de quartzo e feldspato alcalino evidenciado pela continuidade ótica dos grãos de quartzo. 
correlação negativa entre $\mathrm{SiO}_{2}$ e todos os demais elementos $\left(\mathrm{Fe}_{2} \mathrm{O}_{3 \text { total }}, \mathrm{MgO}, \mathrm{MnO}, \mathrm{TiO}_{2}, \mathrm{CaO}, \mathrm{Al}_{2} \mathrm{O}_{3}\right.$ e $\left.\mathrm{P}_{2} \mathrm{O}_{5}\right)$. $\mathrm{O}$ mesmo comportamento é exibido para $\mathrm{SiO}_{2}$ versus alguns elementos traços ( $\mathrm{Zr}$, Ba e $\mathrm{Sr}$ ), como é mostrado na Fig. 8. Fracionamentos de ilmenita, magnetita, plagioclásio, apatita e zircão são passíveis de diminuir os conteúdos dos elementos mencionados. Essas correlaçóes negativas indicam que o magma em questão sofreu modificação fortemente controlada por processo de cristalização fracionada ou segregação mineral durante o fluxo magmático. As variaçóes de $\mathrm{Zr}$, Sr e Ba são geralmente usadas para estimar o grau de fracionamento e especular os processos petrogenéticos que controlaram a evolução de um corpo magmático (Hanson 1989, Dall'Agnol et al. 1999). Wedepohl (1972) mostra que o Ba é admitido mais facilmente no feldspato potássico e nas micas, mas teores significativos

Tabela 1. Dados litoquímicos do Granito Terra Nova (elementos maiores expressos em \%peso e traços em ppm)

\begin{tabular}{|c|c|c|c|c|c|c|c|c|c|c|c|c|c|c|c|c|c|}
\hline 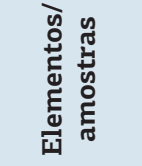 & 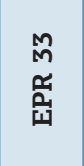 & 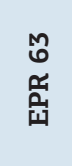 & 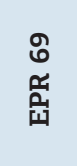 & $\begin{array}{l}\stackrel{0}{N} \\
\text { 品 } \\
\text { 岀 }\end{array}$ & $\begin{array}{l}\stackrel{\infty}{N} \\
\underset{\sim}{\Delta} \\
\stackrel{\sim}{4}\end{array}$ & 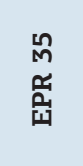 & 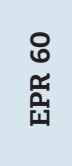 & $\begin{array}{l}\stackrel{n}{m} \\
\widetilde{a} \\
\text { 岀 }\end{array}$ & $\begin{array}{l}\stackrel{\sim}{N} \\
\text { 品 } \\
\text { 㟧 }\end{array}$ & $\begin{array}{l}\tilde{n} \\
\widetilde{a} \\
\text { 岀 }\end{array}$ & $\begin{array}{l}\text { Ñ } \\
\widetilde{a} \\
\text { M }\end{array}$ & $\begin{array}{l}\text { M } \\
\text { ñ } \\
\text { 㟔 }\end{array}$ & 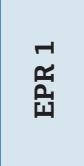 & $\begin{array}{l}\widehat{N} \\
\text { 品 } \\
\text { 崩 }\end{array}$ & 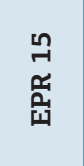 & 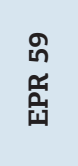 & 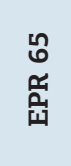 \\
\hline $\mathrm{SiO}_{2}$ & 68,91 & 70,58 & 71,98 & 73,23 & 73,86 & 73,92 & 74,06 & 74,1 & 74,16 & 74,49 & 74,53 & 74,7 & 74,81 & 75,71 & 76,04 & 77,06 & 77,19 \\
\hline $\mathrm{TiO}_{2}$ & 0,52 & 0,31 & 0,37 & 0,29 & 0,19 & 0,23 & 0,19 & 0,21 & 0,22 & 0,2 & 0,26 & 0,17 & 0,22 & 0,17 & 0,11 & 0,12 & 0,11 \\
\hline $\mathrm{Al}_{2} \mathrm{O}_{3}$ & 14,54 & 14,53 & 13,62 & 13,12 & 12,95 & 13,19 & 13,26 & 13,07 & 13,11 & 13,09 & 13,1 & 13,06 & 13,1 & 12,27 & 12,83 & 12,27 & 11,97 \\
\hline $\mathrm{Fe}_{2} \mathrm{O}_{3}{ }^{\mathrm{t}}$ & 3,19 & 3,26 & 3,09 & 2,33 & 2,19 & 2,09 & 2,21 & 1,89 & 5,1 & 2,36 & 1,67 & 2,15 & 1,42 & 1,62 & 1,13 & 1,61 & 1,64 \\
\hline $\mathrm{MnO}$ & 0,14 & 0,05 & 0,07 & 0,09 & 0,04 & 0,09 & 0,07 & 0,09 & 0,08 & 0,06 & 0,05 & 0,06 & 0,04 &, 03 & 0,06 & 0,03 & 0,02 \\
\hline $\mathrm{MgO}$ & 0,51 & 0,62 & 0,47 & 0,32 & 0,11 & 0,24 & 0,23 & 0,25 & 0,18 & 0,23 & 0,17 & 0,19 & 0,18 & 0,29 & 0,08 & 0,11 & 0,18 \\
\hline $\mathrm{CaO}$ & 1,05 & 1,63 & 1 & 0,73 & 0,48 & 0,61 & 0,68 & 0,69 & 0,57 & 0,62 & 0,58 & 0,47 & 0,44 & 0,49 & 0,43 & 0,31 & 0,34 \\
\hline $\mathrm{Na}_{2} \mathrm{O}$ & 4,71 & 4 & 3,63 & 4,01 & 3,6 & 4,04 & 3,95 & 3,9 & 4,44 & 3,82 & 3,64 & 3,76 & 3,81 & 3,37 & 3,94 & 89 & 3,52 \\
\hline $\mathrm{K}_{2} \mathrm{O}$ & 5,27 & 4,15 & 4,71 & 4,95 & 5,54 & 5,01 & 5,08 & 5,03 & 5,05 & 4,91 & 5,46 & 5,16 & 5,39 & 5,14 & 4,89 & 4,61 & 4,88 \\
\hline $\mathrm{P}_{2} \mathrm{O}_{5}$ & 0,15 & 0,03 & 0,08 & 0,08 & 0,04 & 0,06 & $<0,01$ & 0,06 & 0,04 & $<0,01$ & 0,04 & 0,01 & 0,03 & 0,03 & 0,02 & 0,01 & 0,01 \\
\hline P.F. & 0,70 & 0,7 & 0,8 & 0,7 & 0,9 & 0,4 & 0,2 & 0,6 & 0,7 & 0,1 & 0,4 & 0,2 & 0,5 & 0,8 & 0,4 & 0 & 0,2 \\
\hline Soma & 99,68 & 99,81 & 99,81 & 99,86 & 99,88 & 99,9 & 99,9 & 99,89 & 99,92 & 99,89 & 99,9 & 99,91 & 99,94 & 99,96 & 99,96 & 99,98 & 99,96 \\
\hline $\begin{array}{c}\mathrm{FeO}^{\mathrm{t}} / \\
\left(\mathrm{FeO}^{t}+\mathrm{MgO}\right)\end{array}$ & 0,86 & 0,84 & 0,86 & 0,87 & 0,95 & 0,89 & 0,9 & 088 & 0,88 & 0,91 & 0,9 & 0,92 & 0,88 & 0,84 & 0,93 & 0,93 & 0,9 \\
\hline $\mathrm{K}_{2} \mathrm{O} / \mathrm{Na}_{2} \mathrm{O}$ & 1,11 & 1,03 & 1,29 & 1,23 & 1,53 & 1,24 & 1,28 & 1,28 & 1,13 & 1,28 & 1,5 & 1,37 & 1,41 & 1,52 & 1,24 & 1,18 & 1,38 \\
\hline $\mathrm{A} / \mathrm{CNK}$ & 1,32 & 1,49 & 1,46 & 1,35 & 1,35 & 1,37 & 1,37 & 1,36 & 1,31 & 1,40 & 1,35 & 1,39 & 1,36 & 1,36 & 1,39 & 39 & 1,37 \\
\hline $\mathrm{Ba}$ & 1841 & 1041 & 921 & 621 & 542 & 520 & 548 & 518 & 288 & 635 & 442 & 536 & 195 & 168 & 125 & 160 & 302 \\
\hline $\mathrm{Rb}$ & 115,8 & 139,5 & 185,1 & 174,1 & 285,4 & 212,8 & 193,4 & 209 & 337,6 & 149,2 & 102,5 & 190,5 & \begin{tabular}{|l|}
180,1 \\
\end{tabular} & 270,1 & 403,9 & 98 & 206,9 \\
\hline $\mathrm{Sr}$ & 148,2 & 308,3 & 204,2 & 132 & 52,1 & 96,9 & 106,5 & 99,2 & 60,5 & 129,8 & 84,4 & 100,2 & 32 & 36,8 & 29 & 24 & 36,2 \\
\hline $\mathrm{Zr}$ & 412,6 & 244 & 261,8 & 241,2 & 241,8 & 199,7 & 151,5 & 188,2 & 232 & 172,5 & 238,5 & 161,3 & 212,8 & 152 & 135,2 & 97,2 & 102 \\
\hline $\mathrm{Nb}$ & 19,2 & 16,5 & 18,2 & 22,4 & 19,6 & 22,3 & 15 & 19,6 & 52,7 & 15,8 & 13,6 & 14,7 & 18,3 & 22,4 & 42,3 & 0,1 & 20,5 \\
\hline $\mathrm{Y}$ & 9 & 22,7 & 53,1 & 42,3 & 52,9 & 31,8 & 25,8 & 36,3 & 28,4 & 38,3 & 42,7 & 31 & 33,3 & 26,5 & 53,5 & 18,9 & 16,4 \\
\hline $\mathrm{Ga}$ & 21,8 & 17 & 16,9 & 19 & 18,9 & 19,2 & 17 & 18,7 & 22,1 & 17 & 15,4 & 17,2 & 17,3 & 16,9 & 21,2 & 13,7 & 16,1 \\
\hline Th & 11,4 & 16,1 & 23,2 & 24 & 29,6 & 20,1 & 12,4 & 21,7 & 37,5 & 11,7 & 9,4 & 15,1 & 8,1 & 30 & 49,1 & 7,8 & 25,2 \\
\hline $\mathrm{U}$ & 2,3 & 4,2 & 5,7 & 4,3 & 5,3 & 5 & 2,9 & 5,4 & 27,7 & 2,5 & 1,4 & 45 & 2,2 & 6,6 & 18,7 & 2,8 & 3,4 \\
\hline Co & 1,2 & 4, & 2 & 1,6 & 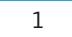 & 1,1 & 1,2 & 1, & 1 & 1,1 & 0,9 & 1,4 & 0,6 & 1,4 & 7 & 0,6 & 0,5 \\
\hline $\mathrm{Ni}$ & 1,8 & 7,4 & 2,4 & 1,7 & 2,6 & 2,1 & 1,9 & 1,6 & 0,8 & 1,6 & 1,4 & 2,3 & - & 1,2 & 0,8 & 0,9 & 1,6 \\
\hline $\mathrm{Cu}$ & 3,7 & 3,4 & 21,4 & 3,9 & 5,2 & 4,6 & 6,6 & 3,4 & 2 & 1,4 & 3,6 & 7,6 & 2,4 & 3,4 & 1,3 & 3,6 & 6,4 \\
\hline $\mathrm{Zn}$ & 85 & 36 & 67 & 58 & 24 & 40 & 54 & 61 & 35 & 40 & 35 & 41 & 23 & 11 & 14 & 11 & 12 \\
\hline $\mathrm{La}$ & 71,2 & 45,9 & 66,3 & 55,8 & 79,2 & 44,4 & 39,6 & 48 & 48,5 & 34,3 & 57,8 & 34,5 & 32,3 & 53,4 & 39,5 & 36,9 & 50,8 \\
\hline $\mathrm{Ce}$ & 170,7 & 83,8 & 132,3 & 131,1 & 151 & 100,7 & 77,3 & 112,5 & 95 & 81,4 & 137,9 & 69,4 & 79 & 115,8 & 93,5 & 6,2 & 57,1 \\
\hline $\mathrm{Nd}$ & 75,3 & 31,1 & 54,8 & 49,4 & 50,9 & 35,6 & 25,8 & 38,2 & 26,1 & 37,4 & 54,3 & 27,7 & 34,4 & 35,8 & 30,2 & 26,2 & 19,2 \\
\hline $\mathrm{Sm}$ & 12,6 & 5,53 & 10,51 & 8,44 & 7,99 & 5,66 & 4,92 & 6,3 & 4,24 & 6,84 & 8,93 & 4,9 & 6,32 & 5,53 & 6,11 & 4,95 & 2,2 \\
\hline $\mathrm{Eu}$ & 2,44 & 0,84 & 1,51 & 0,93 & 0,69 & 0,61 & 0,61 & 0,76 & 0,54 & 0,78 & 0,85 & 0,62 & 0,41 & 0,34 & 0,19 & 0,35 & 0,33 \\
\hline $\mathrm{Gd}$ & 11,1 & 4,39 & 9,03 & 7,15 & 7,42 & 4,73 & 3,97 & 5,56 & 3,47 & 5,33 & 7,76 & 4,26 & 5,68 & 4,55 & 5,84 & 3,8 & 2,22 \\
\hline Dy & 9,74 & 4,09 & 8,77 & 7,13 & 6,72 & 4,37 & 4,15 & 5,58 & 3,91 & 5,63 & 6,91 & 4,54 & 5,28 & 4,07 & 6,97 & 3,17 & 2,06 \\
\hline Er & 5,69 & 2,07 & 5,69 & 4,62 & 4,54 & 3,14 & 2,84 & 3,82 & 2,99 & 3,81 & 4,21 & 3,4 & 3,29 & 2,7 & 5,17 & 1,8 & 1,62 \\
\hline $\mathrm{Yb}$ & 5,23 & 1,97 & 5,61 & 4,87 & 4,67 & 3,66 & 3,11 & 4,29 & 4,04 & 4,7 & 4,19 & 3,57 & 3,35 & 3,19 & 6,2 & 1,61 & 2,79 \\
\hline $\mathrm{Lu}$ & 0,77 & 0,31 & 0,85 & 0,72 & 0,69 & 0,57 & 0,49 & 0,63 & 0,66 & 0,65 & 0,56 & 0,53 & 0,49 & 0,47 & 0,92 & 0,24 & 0,46 \\
\hline $\mathrm{Ga} / \mathrm{Al}$ & 2,83 & 2,21 & 2,35 & 2,74 & 2,76 & 2,75 & 2,42 & 2,70 & 3,19 & 2,45 & 2,22 & 2,49 & 2,50 & 2,60 & 3,12 & 2,11 & 2,54 \\
\hline$+\mathrm{Y}+\mathrm{Nb}+\mathrm{Zr}$ & 657 & 367 & 465 & 437 & 465 & 355 & 270 & 357 & 408 & 308 & 436 & 276 & 343 & 317 & 325 & 192 & 196 \\
\hline $\mathrm{M}$ & 1,64 & 1,45 & 1,39 & 1,47 & 1,41 & 1,44 & 1,44 & 1,44 & 1,52 & 1,39 & 1,41 & 1,42 & 1,4 & 1,36 & 1,37 & 1,35 & 1,35 \\
\hline $\begin{array}{l}\text { saturação } \\
\text { zircao }\left({ }^{\circ} \mathrm{C}\right)\end{array}$ & 855 & 820 & 831 & 817 & 822 & 802 & 778 & 797 & 810 & 793 & 821 & 785 & 811 & 784 & 773 & 748 & 752 \\
\hline
\end{tabular}


podem ocorrer em plagioclásios intermediários. As amostras do Granito Terra Nova, quando plotadas no diagrama R1 e R2 (De La Roche et al. 1980), mostram alinhamento coerente para rochas de afinidade alcalina (Fig. 9).

O Granito Terra Nova apresenta caráter metaluminoso a peraluminoso (Fig. 10), revelado no diagrama $\mathrm{Al}_{2} \mathrm{O}_{3} /$ $\left(\mathrm{CaO}+\mathrm{Na}_{2} \mathrm{O}+\mathrm{K}_{2} \mathrm{O}\right)$ versus $\mathrm{Al}_{2} \mathrm{O}_{3} /\left(\mathrm{Na}_{2} \mathrm{O}+\mathrm{K}_{2} \mathrm{O}\right)$, de Shand (1943) e Maniar \& Piccoli (1989). Pearce et al. (1984) e, posteriormente, Pearce (1996), propuseram um diagrama que usa os elementos $\mathrm{Y}, \mathrm{Nb}$ e $\mathrm{Rb}$ para discriminar ambientes tectônicos. Os autores basearam seus estudos em dados de rochas de ambientes tectônicos conhecidos e de idade Fanerozoica. Aplicando este diagrama para as rochas do Maciço Terra Nova, percebe-se que estas plotam no campo proposto para rochas anorogênicas ou pós-colisionais, como mostra a Fig. 11.

Diagramas multielementos normalizados para o manto primitivo apresentam anomalias negativas de $\mathrm{Ta}$ e $\mathrm{Nb}$, enriquecimento de $\mathrm{K}_{2} \mathrm{O}$, Rb e Th e empobrecimento de $\mathrm{Y}$, Sm, Hf e Ba (Fig. 12A). Padrão de Elementos Terras Raras normalizados
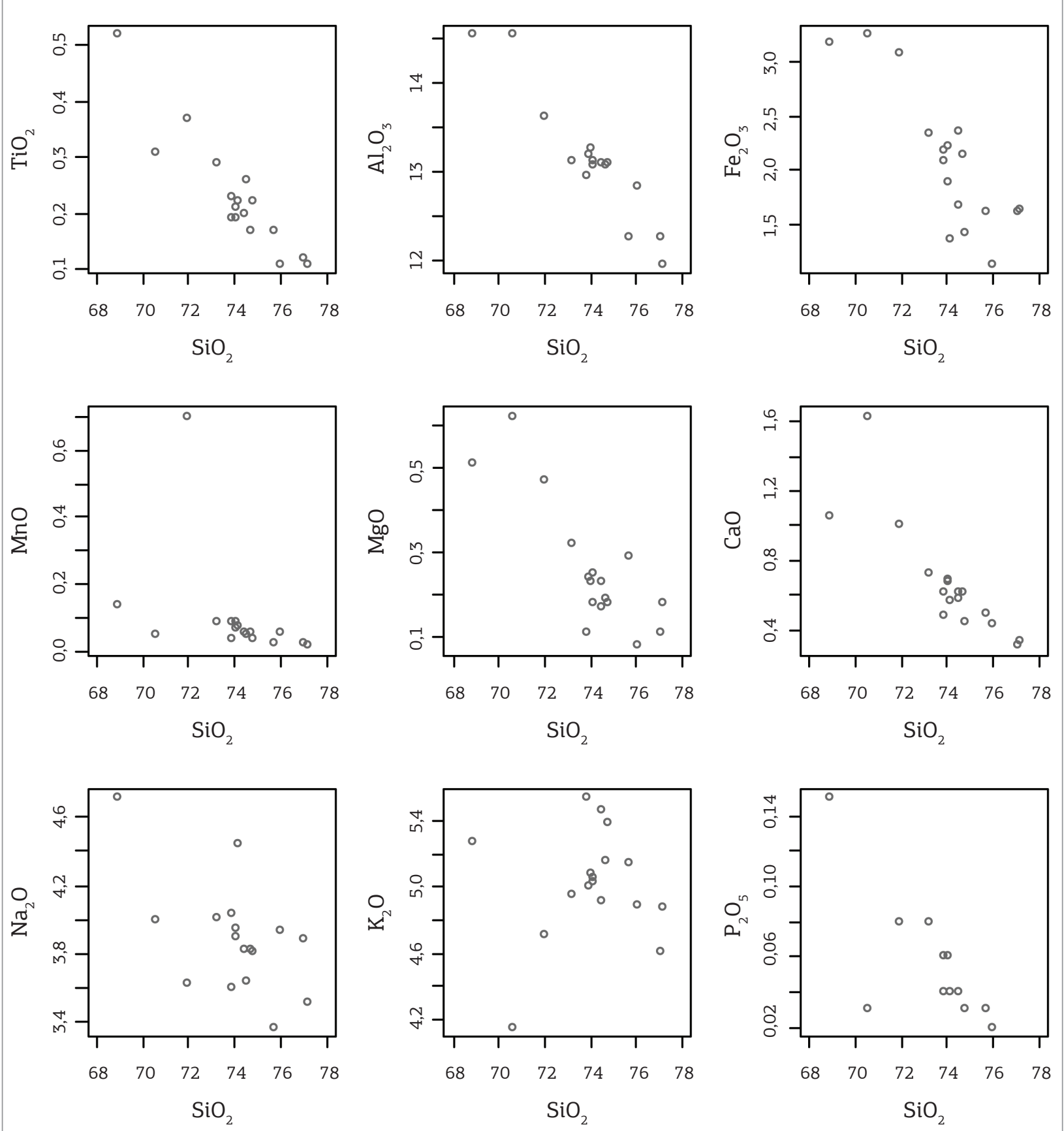

Figura 7. Diagramas binários mostrando correlação negativa entre $\mathrm{SiO}_{2}$ versus elementos maiores. 
para condritos são caracterizados pelo enriquecimento de elementos terra raras leves, anomalia negativa de Eu e padrão retilíneo de elementos terras raras pesados (Fig. 12B).

Eby (1992) propôs que os granitos tipo A originados em ambientes anorogênicos apresentam valores de $\mathrm{Y} / \mathrm{Nb}$ inferiores a 1,2 e origem mantélica, enquanto os originados em outros ambientes tectônicos com fontes crustais podem ser definidos pelas razões $\mathrm{Y} / \mathrm{Nb}$ acima de 1,2. Utilizando os diagramas propostos por este autor (Fig. 13) para os granitos Terra Nova, percebe-se que as amostras plotam no campo dos granitos tipo A2 transicionando para o tipo A1. Os resultados são concordantes com ambiente pós-colisional e sugerem fonte mantélica com pequena contaminação crustal.

Dall'Agnol \& Oliveira (2007) propóem diagramas binários utilizando $\mathrm{CaO}+\mathrm{Al}_{2} \mathrm{O}_{3}$ ou $\mathrm{Al}_{2} \mathrm{O}_{3}$ versus $\mathrm{CaO} /\left(\mathrm{FeO}^{\mathrm{t}}+\mathrm{MgO}+\mathrm{TiO}_{2}\right)$ para separar granitos cálcico-alcalinos de granitos tipo $\mathrm{A}$, enquanto separa os granitos oxidados dos reduzidos utilizando $\mathrm{Al}_{2} \mathrm{O}_{3}$ versus $\mathrm{FeO}^{t} /\left(\mathrm{FeO}^{\mathrm{t}}+\mathrm{MgO}\right)$. O Granito Terra Nova, de acordo com a classificaçáo proposta, é tipo A de caráter dominantemente oxidado (Fig. 14).

Nardi \& Bitencourt (2009) apontam como parâmetros importantes na classificação de granitos tipo A os seguintes itens: elevadas concentraçóes de sílica, $\mathrm{K}_{2} \mathrm{O}+\mathrm{Na}_{2} \mathrm{O}>9 \%$, razóes $\mathrm{Ga} / \mathrm{Al}$ superiores a 2,6, $\mathrm{FeO}^{\mathrm{t}} /\left(\mathrm{FeO}^{\mathrm{t}}+\mathrm{MgO}\right)>0,9$, soma de $\mathrm{Ce}+\mathrm{Y}+\mathrm{Nb}+\mathrm{Zr}$ superiores a 340 . Os autores ressaltam que, para ser considerado granito tipo A, os resultados geoquímicos de um dado corpo devem obedecer a pelo menos um dos critérios mencionados. O Granito Terra Nova atende parte deles, como valor médio da razão $\mathrm{Ga} / \mathrm{Al}$ igual a 2,6, razóes $\mathrm{FeO}^{t} /\left(\mathrm{FeO}^{\mathrm{t}}+\mathrm{MgO}\right)$ variando de 0,82 a 0,95 e soma $\mathrm{Ce}+\mathrm{Y}+\mathrm{Nb}+\mathrm{Zr}$ entre 192 e 657, sugerindo afinidade com magmas tipo A, segundo os autores.

\section{Geotermometria}

O método de saturação de zircão de Watson \& Harrison (1983) pode ser utilizado como geotermômetro

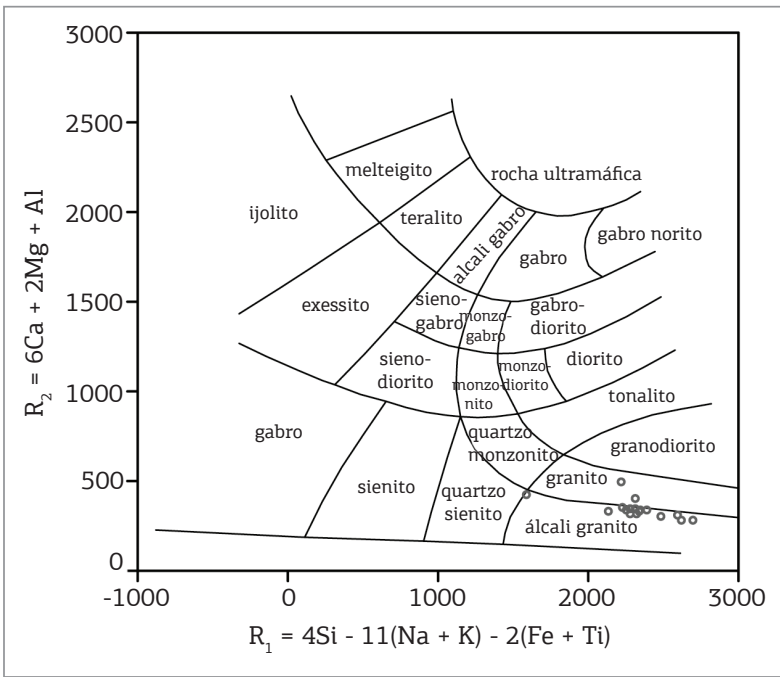

Figura 9. Diagrama classificatório De La Roche (1980) usado para as rochas do Granito Terra Nova.

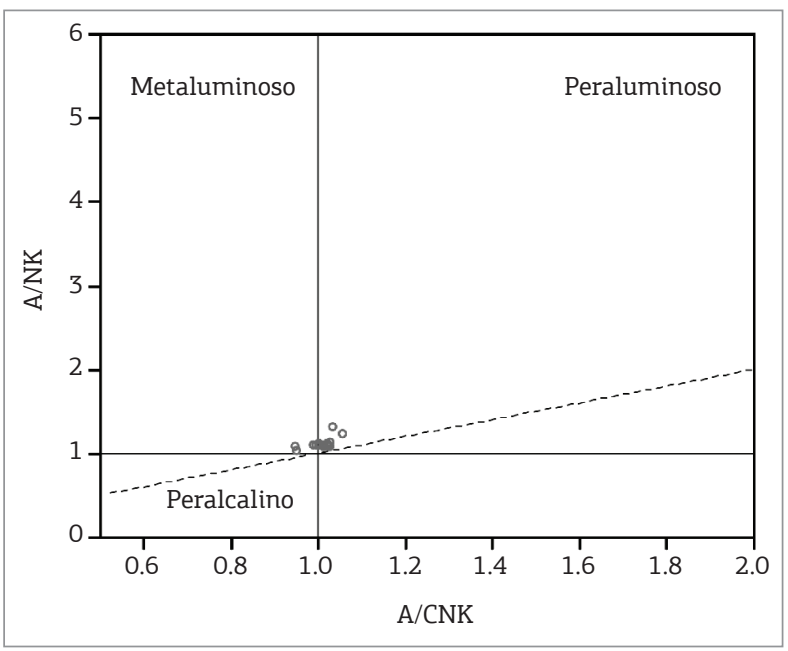

Figura 10. Diagrama de alcalinidade para o Granito Terra Nova (segundo Shand 1943, Maniar \& Piccoli 1989).
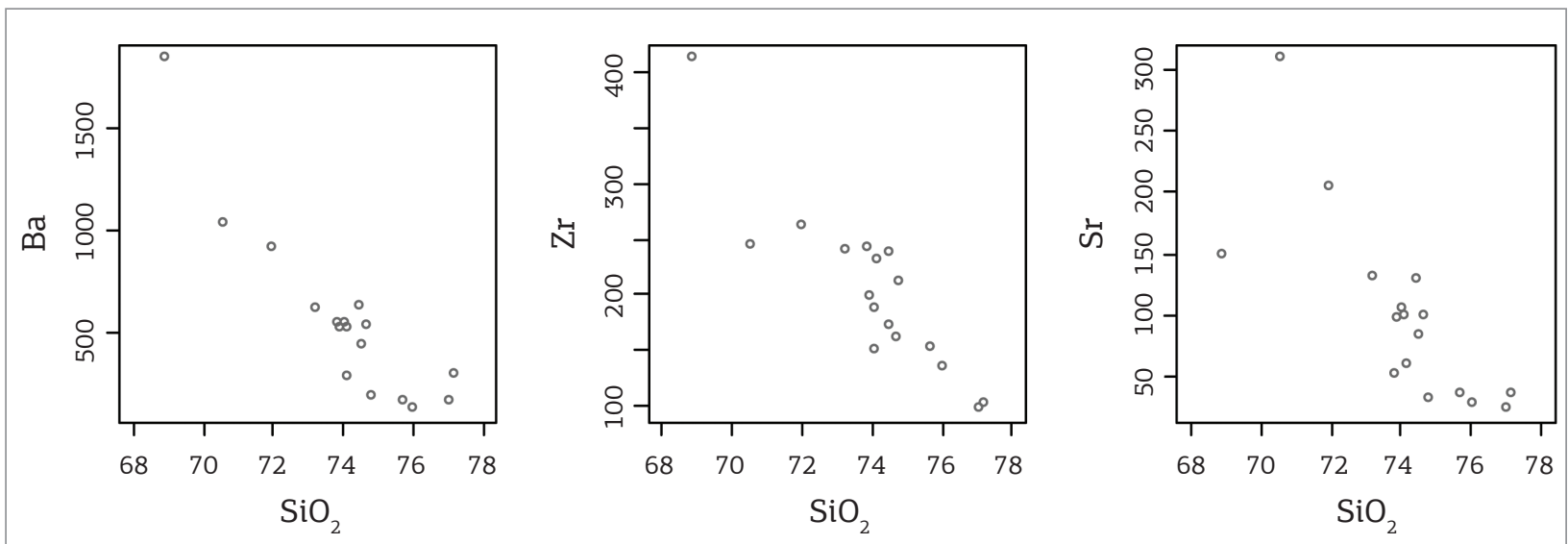

Figura 8. Diagramas binários mostrando correlação negativa entre $\mathrm{SiO}_{2}$ versus $\mathrm{Zr}, \mathrm{Rb}$ e $\mathrm{Ba}$. 


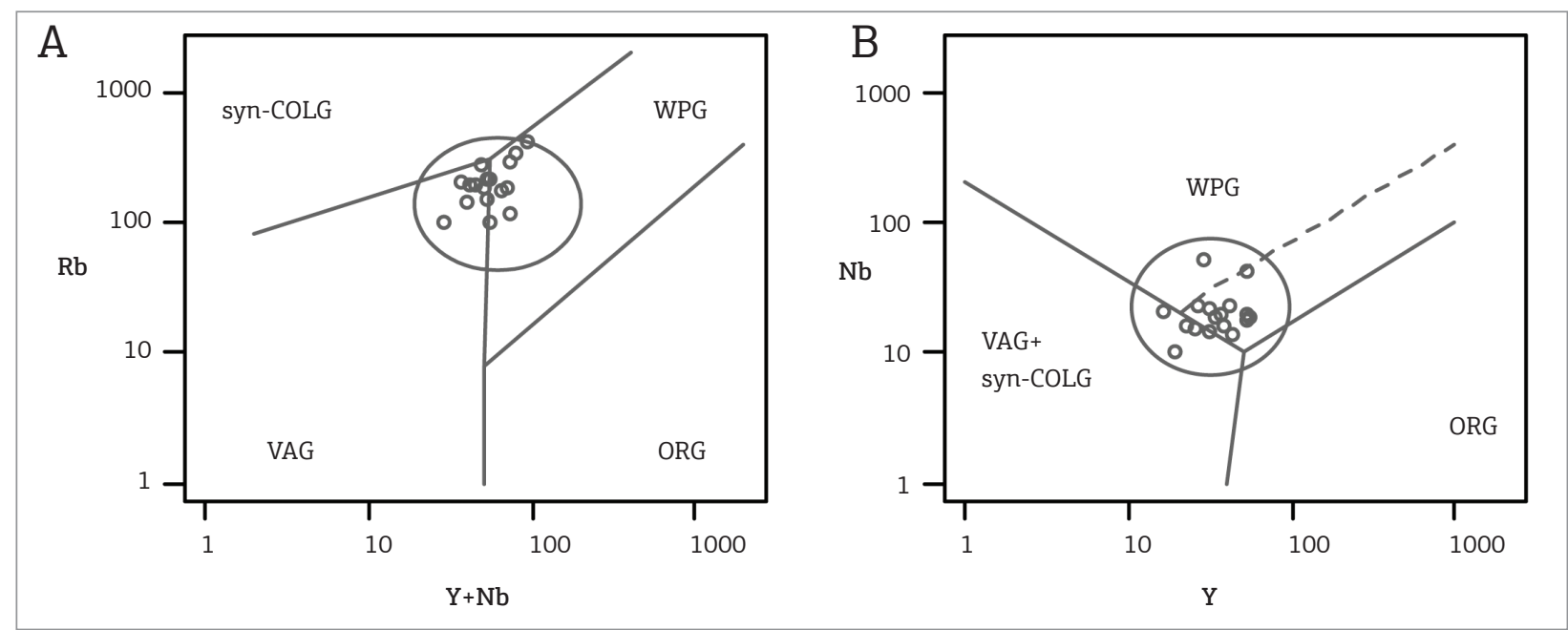

Figura 11. (A) Diagrama Rb versus $\mathrm{Y}+\mathrm{Nb}$ (Pearce et al. 1984, Pearce 1996); (B) Diagrama Nb versus $\mathrm{Y}$ para as rochas do Granito Terra Nova.

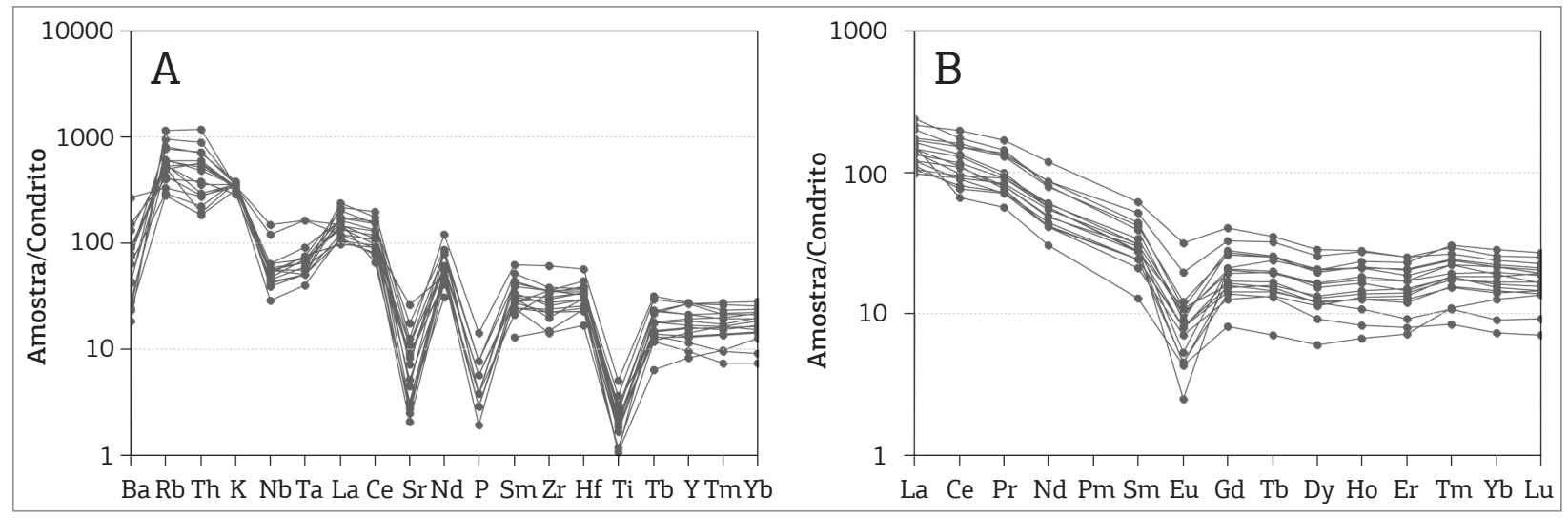

Figura 12. Diagrama de multielementos (A) normalizado pelo padrão condrítico de Thompson (1982) e de elementos terras raras (B) normalizado pelo padrão condrítico de Nakamura (1974) do Granito Terra Nova.
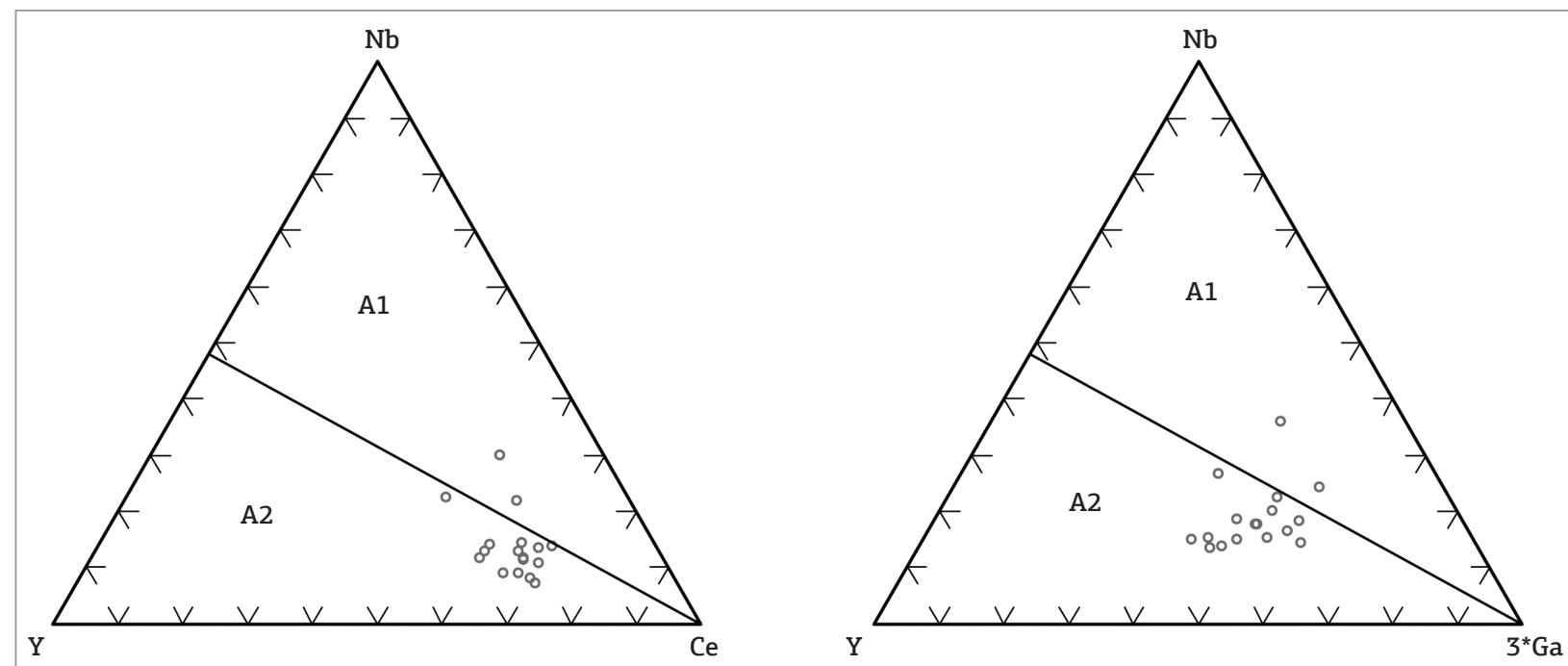

Figura 13. Diagrama de Eby (1992) separando os granitos tipo A, originados em ambientes pós-colisional, dos anorogênicos. 
de líquidos ácidos metaluminosos com valores do parâmetro $\mathrm{M}[\mathrm{M}=(\mathrm{Na}+\mathrm{K}+2 \mathrm{xCa}) /(\mathrm{AlxSi})]$ entre 0,9 e 1,7 (Hanchar \& Watson 2003). As características geoquímicas apresentadas nesse trabalho atendem aos parâmetros estabelecidos por Hanchar \& Watson (2003), expressas pelos valores de $\mathrm{M}$ variando de 1,35 a 1,64 . Como o zircão é um mineral caracteristicamente precoce na ordem de cristalização do Granito Terra Nova, assume-se que a temperatura de saturação do zircão nesse sistema se aproxima da temperatura liquidus do magma granítico.

Os valores de temperatura obtidos para os granitos do Granito Terra Nova variam de 748 a $855^{\circ} \mathrm{C}$ (Tab. 1) e tendem a diminuir dos termos menos diferenciados para os mais diferenciados. A presença de grãos herdados de zircão, conforme demonstrado nos resultados isotópicos pode promover um erro na determinação da temperatura de saturação de zircão de aproximadamente $50^{\circ} \mathrm{C}$, conforme afirmativas de Hanchar \& Watson (2003). Dessa forma, o intervalo de temperatura estimado para a temperatura de saturação de zircão no magma granítico que deu origem ao Granito Terra Nova pode ter variado de aproximadamente
700 para $900^{\circ} \mathrm{C}$. Essa estimativa é coerente com as temperaturas de magmas tipo-A determinadas experimentalmente (Clemens et al. 1986, Patińo Douce 1997, Scaillet \& Pichavant 1999).

\section{RESULTADOS ISOTÓPICOS}

Uma amostra do Granito Terra Nova (EPR-24) foi datada pelo método U-Pb (Tab. 2) no laboratório de geocronologia da UnB, usando Laser Ablation (LA-ICPMS). A Tab. 3 mostra os resultados Sm-Nd. A Fig. 15 mostra os diagramas concórdia obtidos neste estudo.

Duas famílias distintas de zircóes foram encontradas. O primeiro grupo mostra idade concordante $1896 \pm 13 \mathrm{Ma}$ e o outro, com idade discordante, devido à presença de $\mathrm{Pb}$ comum, indica para a cristalização uma idade $1727 \pm 42 \mathrm{Ma}$. No contexto geológico e conhecimento prévio de dados geocronológicos da região, interpretamos a idade de $1896 \pm 13 \mathrm{Ma}$ como referente à herança de zircóes do granito Matupá, encaixante do Granito Terra Nova. A idade do Granito Terra

Tabela 2. Dados isotópicos U-Pb do Granito Terra Nova

\begin{tabular}{|c|c|c|c|c|c|c|c|c|c|c|c|c|c|c|c|c|c|}
\hline \multirow[b]{2}{*}{ 殉号 } & \multirow[b]{2}{*}{$\begin{array}{l}\stackrel{0}{0} \\
\stackrel{0}{4}\end{array}$} & \multirow[b]{2}{*}{$\sum_{\substack{R \\
\text { R }}}^{2}$} & \multicolumn{8}{|c|}{ Razões isotópicas } & \multicolumn{7}{|c|}{ Idades (Ma) } \\
\hline & & & 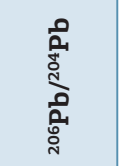 & 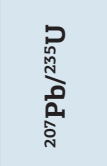 & 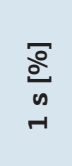 & 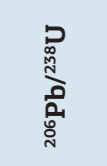 & 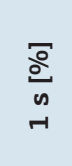 & $\begin{array}{l}\stackrel{\circ}{\circ} \\
\text { 完 }\end{array}$ & 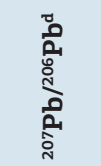 & 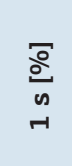 & 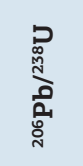 & $\begin{array}{l}n \\
0 \\
0 \\
n \\
-1\end{array}$ & 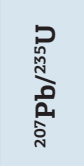 & $\begin{array}{l}n \\
\text { مै } \\
\text { n } \\
-1\end{array}$ & 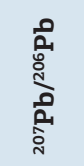 & $\begin{array}{l}n \\
0 \\
n \\
n \\
-1\end{array}$ & 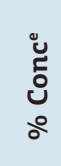 \\
\hline 014-Z9 & UL & & & & & & & & 201 & & 200 & 24 & 589 & 18 & 045 & 0 & 02 \\
\hline 010-Z5 & 1,525 & & 1077 & 4,0018 & 1,95 & 0,2344 & 1,90 & 0,97 & 0,1238 & 0,46 & 358 & & 635 & 16 & 012 & 8 & 67 \\
\hline 016-Z9 & 0,054 &, 40 & 30323 & 4,0400 & 7,31 & 0,2255 & 6,88 & 0,94 & 0,1299 & 2,47 & 1311 & 82 & 642 & 59 & 097 & 43 & 63 \\
\hline 025-Z18 & 0,880 & 43 & 1861 & 4,0940 & 2,52 & 0,2395 & 2,30 & 0,91 & 1240 & 1,03 & 384 & 29 & 653 & 1 & 014 & 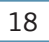 & 69 \\
\hline 027-Z20 & 0,968 & 0,56 & 1667 & 4,4277 & 3,11 & 0,2633 & 2,93 & 0,94 & 0,1220 & 1,03 & 1507 & 39 & 1718 & 26 & 985 & 18 & 76 \\
\hline 028-Z21 & 0,991 & c & 500 & 4,7575 & 2,32 & & & 0,91 & & & 651 & & & 19 & & 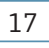 & 86 \\
\hline 015-Z8 & 0,729 &, 62 & 175 & 4,7789 & 1,34 & 0,2 & 1,17 & 0,86 & 0,1190 & 06 & 648 & 17 & 81 & 11 & 42 & 12 & 85 \\
\hline 030-Z23 & 0,063 & & 964 & 4 & 5,3 & & & & & & 092 & & 782 & & & 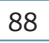 & 90 \\
\hline 005-Z2 & 0,026 & 0,64 & 59635 & 4,9534 & 2,09 & 0,3 & 1,65 & 0,79 & 0,1148 & 1,28 & 1755 & 25 & 1811 & 18 & 77 & 23 & 93 \\
\hline 033-Z24 & 0,024 & 0,55 & 64856 & 5,1822 & 2,02 & 0,3247 & 1,75 & 0,86 & 0,1158 & 1,00 & 813 & 28 & 850 & 17 & 892 & 8 & 96 \\
\hline 026-Z19 & 0,088 & 93 & 17552 & 5,3310 & 2,91 & 0,3 & 1,50 & 0,73 & 0,1179 & 2,50 & 829 & 24 & 874 & 5 & 924 & 5 & 95 \\
\hline 018-Z13 & 0,062 & 1,02 & 21710 & 5,3582 & 2,77 & 0,3412 & 2,07 & 0,74 & & 1,84 & 892 & 34 & & 4 & 3 & 3 & 102 \\
\hline 017-Z12 & & & & & & & & & & & & & & 20 & & 4 & \\
\hline 018-Z11 & 0,299 & 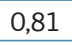 & 5139 & 5,4394 & 2,06 & 0,3427 & 1,86 & 0,96 & 01151 & 0,90 & 900 & 31 & 1891 & 18 & 882 & 16 & 01 \\
\hline 015-Z10 & 0,030 & - & 50548 & 5,5386 & 1,84 & 0,3483 & & 0,76 & כנה & & 927 & J & 1907 & 0 & 35 & 1 & 02 \\
\hline 012-Z7 & 0,221 & 1 & 6907 & 5,5553 & 1,31 & 0,3561 & 0,98 & 0,86 & 0,1131 & 0,86 & 1964 & 17 & 1909 & 11 & 51 & 16 & 106 \\
\hline 013-Z8 & 0,025 & 0,72 & 60503 & 5,5591 & 1,82 & 0,3365 & 1,39 & 0,75 & 0,1198 & 1,18 & 1870 & 23 & 1910 & 16 & 1954 & 21 & 96 \\
\hline 034-Z25 & 0,031 & 0,73 & 50083 & 5,5704 & 1,96 & 0,3512 & 1,65 & 0,84 & 0,1150 & 1,06 & 1941 & 28 & 1912 & 17 & 1880 & 19 & 103 \\
\hline 029-Z22 & 0,011 & 0,45 & 41848 & 5,5813 & 2,68 & 0,3524 & 2,23 & 0,83 & 0,1149 & 1,49 & 1946 & 37 & 1913 & 23 & 1878 & 27 & 104 \\
\hline 007-Z4 & 0,029 & 1,01 & 51940 & 5,6182 & 1,64 & 0,3490 & 1,24 & 0,75 & 0,1168 & 1,07 & 1930 & 21 & 1919 & 14 & 1907 & 19 & 01 \\
\hline 008-Z5 & 0,032 & 0,95 & 46930 & 5,6887 & 2,42 & 0,3573 & 2,06 & 0,85 & 0,1155 & 1,28 & 1970 & 35 & 1930 & 21 & 1887 & 23 & 04 \\
\hline 036-Z27 & 0,050 & 1,08 & 29569 & 6,2201 & 4,51 & 0,3988 & 1,80 & 0,63 & 0,1131 & 4,13 & 2164 & 33 & 2007 & 39 & 1850 & 75 & 117 \\
\hline 004-Z1 & 0,578 & 0,39 & 3051 & 2,2232 & 3,11 & 0,1110 & 3,03 & 0,97 & 0,1453 & 0,70 & 679 & 20 & 1188 & 22 & 2291 & 12 & 30 \\
\hline 037-Z28 & 0,398 & 0,44 & 4215 & 3,6745 & 2,86 & 0,1961 & 2,36 & 0,82 & 0,1359 & 1,62 & 1155 & 25 & 1566 & 23 & 2175 & 28 & 53 \\
\hline
\end{tabular}


Tabela 3. Dados isotópicos de Sm-Nd do Granito Terra Nova

\begin{tabular}{c|c|c|c|c|c|c|c|c|c}
\hline Amostra & $\mathbf{S m}(\mathbf{p p m})$ & $\mathbf{N d}(\mathbf{p p m})$ & $\mathbf{S m} / \mathbf{N d}$ & $\mathbf{S m}^{\mathbf{1 4 7}} / \mathbf{N d}^{\mathbf{1 4 4}}$ & $\mathbf{N d}^{143} / \mathbf{N d}^{144}$ & $\pm \mathbf{2 s}$ & $\varepsilon_{\mathbf{N d}(0)}$ & $\mathbf{e}_{\mathbf{N d}(\mathbf{T})}{ }^{*}$ & $\mathbf{T D M}(\mathbf{G a})$ \\
\hline EPR-33 & 6,65 & 33,54 & 0,1982 & 0,1199 & 0,5117 & 0,000005 & $-18,3$ & $-0,98$ & 2,17 \\
\hline EPR-60 & 5,92 & 35,42 & 0,1671 & 0,101 & 0,51155 & 0,00001 & $-21,2$ & 0,36 & 2,00 \\
\hline EPR-63 & 12,45 & 63,17 & 0,1971 & 0,1191 & 0,511721 & 0,000012 & $-17,9$ & $-0,38$ & 2,11 \\
\hline EPR-69 & 13,67 & 75,05 & 0,1821 & 0,1101 & 0,511691 & 0,000009 & $-18,5$ & 1,07 & 2,17 \\
\hline
\end{tabular}
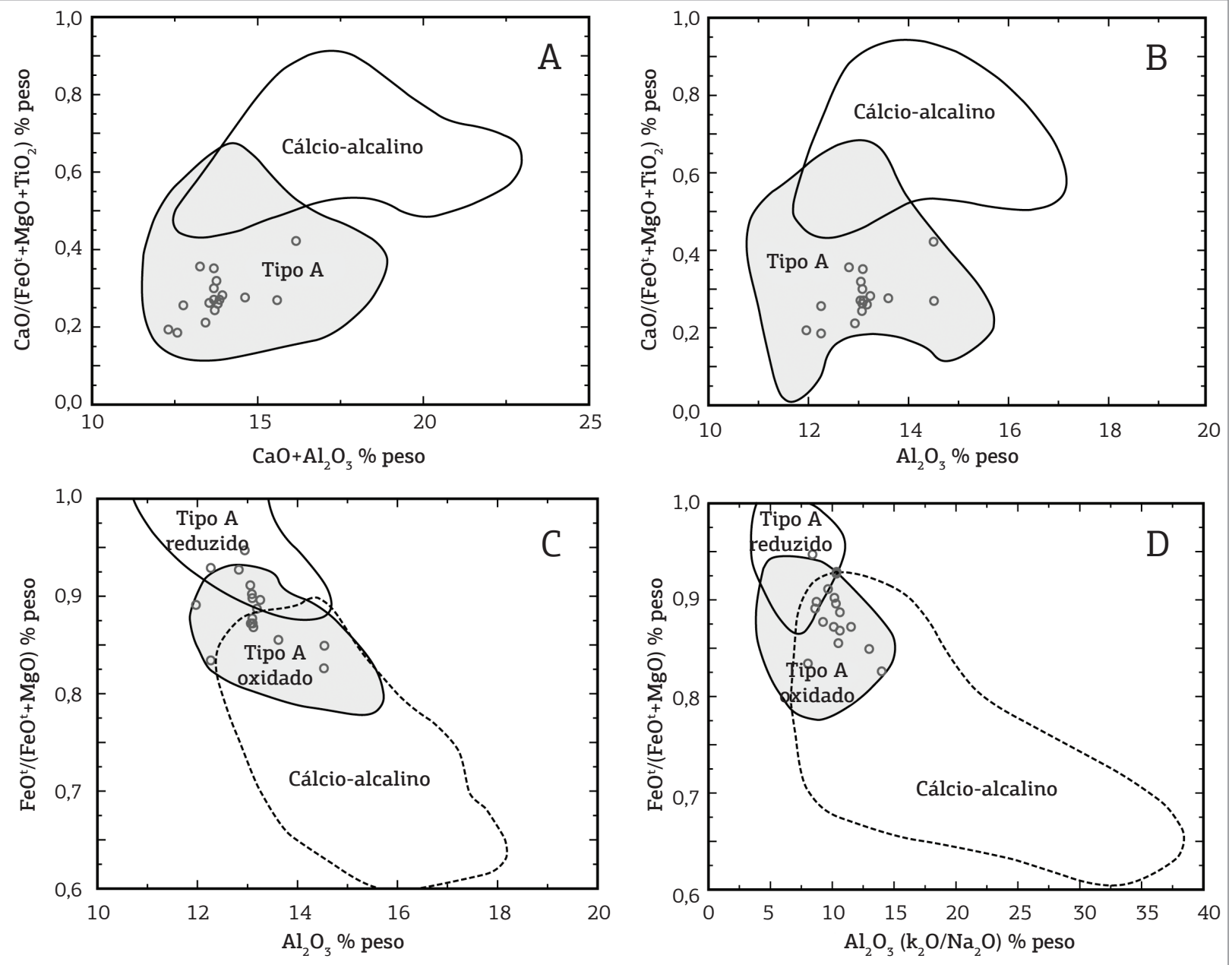

Figura 14. Diagramas discriminatórios entre granitos tipo A e cálcio-alcalinos (A e B) e entre granitos tipo A reduzidos e oxidados e cálcio-alcalino, segundo Dall'Agnol \& Oliveira (2007).

Nova está, portanto, representada pelos zircóes alinhados em $1727 \pm 42 \mathrm{Ma}$. A presença de $\mathrm{Pb}$ comum nos zircóes desse grupo geram um erro elevado. Entretanto, considerando o erro analítico, estes dados são próximos aos obtidos por Santos et al. (2000) para o Granito Teles Pires que aflora na Serra Formosa (1760 Ma), de Santos et al. (2000) apresentados por Lacerda Filho (2004) para biotita granito da região de Terra Nova do Norte (1757 $\pm 16 \mathrm{Ma}$ ) e por Pinho et al. (2003) para granitoides da regiáo de Moriru (1763 $\pm 6 \mathrm{Ma}, 1759 \pm 3 \mathrm{Ma})$.

Os resultados dos estudos isotópicos $\mathrm{Sm}-\mathrm{Nd}$ do Granito Terra Nova mostram valores de idade Modelo consistentes com os resultados apresentados por outros autores (valores de 2,0 a 2,1 Ga) e $\varepsilon N d$ variando de 1,07 a -0,98 (Tab. 2)

\section{CONCLUSÕES}

O Granito Terra Nova é um granito rapakivi do tipo A, de afinidade alcalina, metaluminoso a peraluminoso, com características geoquímicas de granitos de ambiente pós-colisional.

Os teores de elementos maiores e traços são consistentes com uma evolução magmática por cristalização fracionada ou segregação mineral, e participação de plagioclásio, apatita, óxidos de Fe-Ti e zircão. Estimativas com base nas temperaturas de saturação de zircão indicam temperaturas de cristalização entre 748 e $855^{\circ} \mathrm{C}$. A presença 


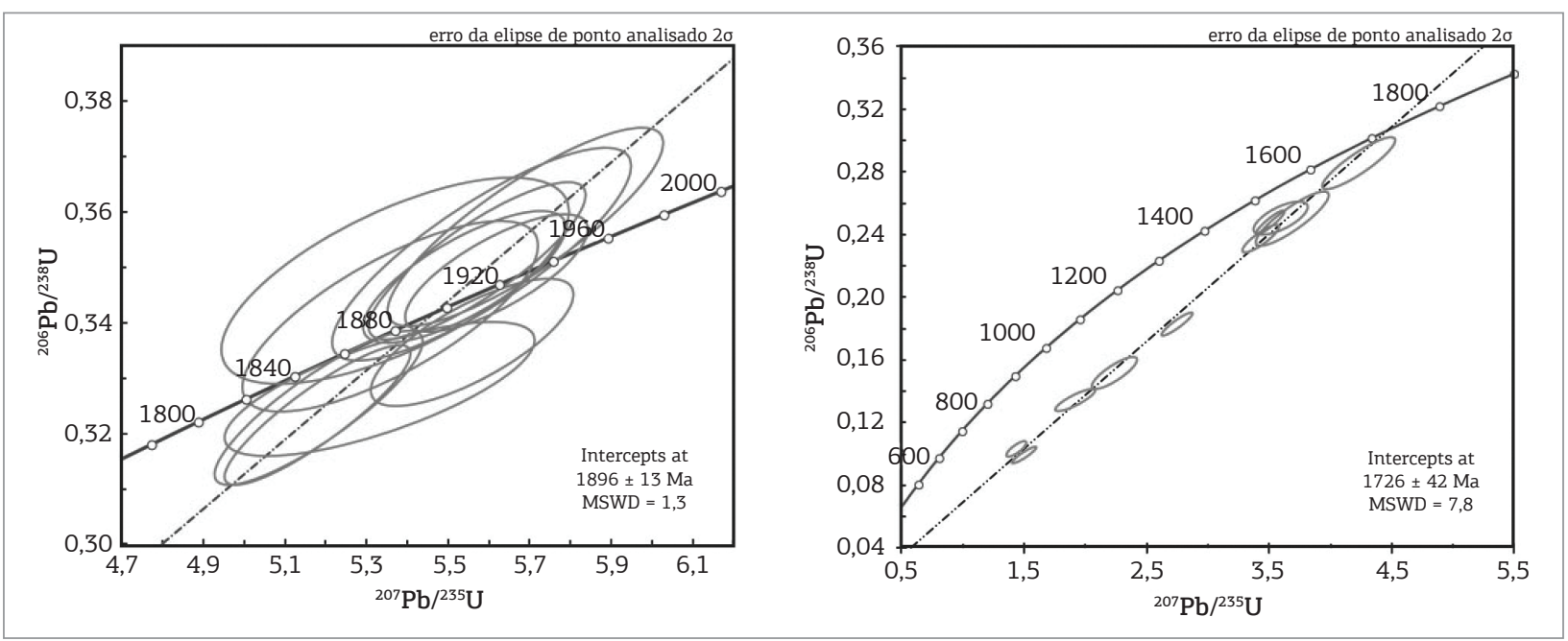

Figura 15. Diagramas geocronológicos da população de zircões herdados (A) e zircões representativos da idade de cristalização da rocha (B).

de enclaves máficos microgranulares associados aos valores positivos de $\varepsilon_{\mathrm{Nd}}$ e da tendência metaluminosa sugerem participação de fontes mantélicas na evolução do Granito Terra Nova. Entretanto, a variação dos teores de $\mathrm{Al}_{2} \mathrm{O}_{3}$, valores de $\varepsilon_{\mathrm{Nd}}$ positivos e a presença de zircóes herdados com idades compatíveis com a Suíte Intrusiva Matupá sugerem contribuição crustal.

O resultado de datação $\mathrm{U}-\mathrm{Pb}(1.727 \pm 42 \mathrm{Ma})$ é compatível com idades previamente apresentadas para o Teles Pires, em torno de 1756 Ma. Essa idade é caracterizada no Cráton Amazônico por uma granitogênese pós-colisional, nesta área representada pelo Granito Terra Nova.

\section{AGRADECIMENTOS}

Os autores agradecem à Coordenação de Aperfeiçoamento e Pessoal de Nível Superior (CAPES) pela concessão de bolsa mestrado à autora Ezenildes Silva Prado, ao Programa Nacional de Cooperação Acadêmica da Universidade Federal de Mato Grosso/Universidade Estadual de Campinas (PROCAD UFMT/UNICAMP), ao GEOCIAM, ao Programa de Pós-Graduaçáo em Geociências da UFMT, os laboratórios de Geocronologia da UnB e da UFRGS, aos professores da UFMT e a todos os colegas que ajudaram na realização deste trabalho, além dos revisores anônimos pelas sugestôes e contribuiçóes para melhora do texto original.

\section{REFERÊNCIAS}

Alves C.L., Sabóia A.M., Martins E.G., Stropper J.L. (orgs.). 2010. Geologia e recursos minerais das Folhas São José do Xingu SC.22Y-A e Rio Comandante Fontoura SC.22-Y-B. Goiânia, CPRM/SICMEMT, escala 1:250.000.

Barros C.E.M., Macambira M.J.B., Barbey P., Scheller T. 2004. Dados isotópicos $\mathrm{Pb}-\mathrm{Pb}$ em zircão (evaporação) e Sm-Nd do Complexo Granítico Estrela, Província Mineral de Carajás, Brasil: implicações petrológicas e tectônicas. Revista Brasileira de Geociências, 34(4):531-538.

Barros M.A.S., Chemale Jr. F., Nardi L.V.S., Lima E.F. 2009. Paleoproterozoic bimodal post-collisional magmatism in the southwestern Amazonian Craton, Mato Grosso, Brazil: geochemistry and isotopic evidence. Journal of South American Earth Sciences, 27(1):11-23.

Bettencourt J.S., Tosdal R.M., Leite Jr. W.B., Payolla, B. L. 1999. Mesoproterozoic rapakivi granites of the Rondônia Tin Province, southwestern border of the Amazonian Craton, Brazil - I. Reconnaissance $\mathrm{U}-\mathrm{Pb}$ geochronology and regional implications. Precrambrian Research, 95(1-2):41-67
Clemens J.D., Holloway J.R., White A.J.R. 1986. Origin of an A-type granite: experimental constraints. American Mineralogist, 71:371-324.

Dall'Agnol R. \& Oliveira D.C. 2007. Oxidized, magnetite-series, rapakivi-type granites of Carajás, Brazil: implications for classification and petrogenesis of A-type granites. Lithos, 93(3-4):215-233.

Dardene M.A. \& Schobbenhaus C. 2001. Metalogênese do Brasil. Brasília, Editora UNB, 392 p

De la Roche H., Leterrier J., Grandclaude P., Marchal M. 1980. A classification of volcanic and plutonic rocks using $R_{1} R_{2}$-diagram and major-element analyses - its relationship with current nomenclature. Chemical Geology, 29(1-4):183-210.

De Paolo D.J. 1981. Neodymium isotopes in the Colorado Front Range and crust-mantle evolution in the Proterozoic. Nature, 291:193-196.

Eby G.N. 1992. Chemical subdivision of the A-type granitoids: petrogenetic and tectonic implication. Geology, 20(7):641-644.

Frasca A.A.S., Oliveira C.C., Martins E.G., Borges F.R., Moreton L.C., Albuquerque M.C., Villas Boas P.F., Ribeiro P.S.E., Souza J.O. 
2004. Projeto Província Mineral de Alta Floresta - mapa geológico integrado. Goiânia, CPRM, escala 1:500.000. CD-ROM.

Hanchar J.M. \& Watson E.B. 2003. Zircon saturation thermometry. In: Hanchar J.M. \& Hoskin P.W.O. (eds.). Zircon. Review in Mineralogy and Geochemistry, 53:89-112.

Hanson G.N. 1989. An approach to trace element modeling using a simple igneous system as an example. Reviews in Mineralogy and Geochemistry, 21:79-97.

Harker, A. 1909.The natural history of igneous rocks. London, Methuen, $384 \mathrm{p}$.

Janousek V, Farrow C.M., Erban V. 2006. Interpretation of whole-rock geochemical data in igneous geochemistry: introducing Geochemical Data Toolkit (GCDkit). Journal of Petrology, 47(6):1255-1259.

Lacerda Filho J. (org.). 2004. Geologia e recursos minerais do estado do Mato Grosso: texto explicativo do mapa geológico e de recursos minerais do estado do Mato Grosso. Cuiabá, CPRM e SICME-MT, escala 1:1.000.000.

Maniar P.D. \& Piccoli P.M. 1989. Tectonic discrimination of granitoids. The Geological Society of America Bulletin, 101(5):635-643.

Moreton L.C. \& Martins E.G. 2005. Geologia e Recursos Minerais da Folha Vila Guarita - Folha SC.21-Z-B. Brasília, CPRM/DEPAT/DIEDIG, escala 1:250.000

Moura R, 2004. Integração de dados aerogeofísicos, multiespectrais e geoquímicos no segmento leste da Província aurífera Alta Floresta (MT): implicações geológicas e metalogenéticas regionais. Instituto de Geociências, Universidade Estadual de Campinas; Trabalho de Conclusão de Curso; 50p.

Nakamura N. 1974. Determination of REE, Ba, Fe, Mg, Na and K in carbonaceous and ordinary chondrites. Geochimica et Cosmochimica Acta, 38(5):757-775.

Nardi L.V.S. \& Bitencourt M.F. 2009. A-type granitoids in postcollisional settings from southernmost Brazil: their classification and relationship with magmatic series. Canadian Mineralogist, 47:1493-1504

Paes de Barros A.J. 2007. Granitos da região de Peixoto de Azevedo: Novo Mundo e mineralizações auríferas relacionadas - Província Aurifera Alta Floresta (MT). Tese de Doutorado, Instituto de Geociências, Universidade Estadual de Campinas, Campinas, 154 p.

Patchett P.J. \& Ruiz J. 1987. Nd isotopic ages of crust formation and metamorphism in the Precambrian of eastern and southern Mexico. Contributions to Mineralogy and Petrology, 96(4):523-528.

Patiño Douce A.E. 1997. Generation of metaluminous A-type granites by low-pressure melting of calc-alkaline granitoids. Geology, 25(8):743-746.

Pearce J.A. 1996. Sources and settings of granitic rocks. Episodes, 19(4):120-125.
Pearce J.A., Harris N.B.W., Tindle A.G. 1984. Trace elements discrimination of diagrams for the tectonic interpretation of granitic rocks. Journal of Petrology, 25:956-983.

Pinho M.A.S.B., Schmus W.R.V., Chemale Jr. F., Pinho F.E.C., 2003. $\mathrm{U}-\mathrm{Pb}$ ages and Sm-Nd evidence for 1,76-1.77 Ga magmatism in the Moriru region, Mato Grosso, Brazil: implications for province boundaries in the SW Amazon Craton. Precambrian Research, 126(1-2):1-25.

Santos J.O.S., Hartmann L.A., Gaudette H.E., Groves D.I., McNaughton N.J., Fletcher I.R. 2000. New understanding of the Amazon Craton provinces, based on field work and radiogenic isotope data. Gondwana Research, 3(4):453-486.

Scaillet B. \& Pichavant M. 1999. An experimental study of a lower proterozoic A-type granite from the eastern Amazonian Craton, Brazil. Journal of Petrology, 40(11):1673-1698.

Shand S.J. 1943. The eruptive rocks. 2. ed. John Wiley, New York, 444 p. Silva G.H., Leal J.W.L., Montalvão R.M.G. 1980. Geologia. In: BRASIL. Ministério das Minas e Energia. Projeto RADAMBRASIL. Folha SC.21 - Juruena - Levantamento de Recursos Naturais, v. 20, Rio de Janeiro, p. 21-116.

Silva G.H., Leal J.W.L., Salum O.A.L., Dall'Agnol R., Baset M.A.S. 1974. Esboço geológico de parte da Folha SC/21 - Juruena. In: Congresso Brasileiro de Geologia, 28, Anais, p. 309-320.

Silva M.G. \& Abram M.B. (orgs.) 2008. Projeto Metalogenia da Província Aurífera Juruena - Teles Pires, Mato Grosso. Informe de Recursos Minerais, Série Ouro, 16. CPRM, Goiânia, 212 p.

Souza J.P., Frasca A.A.S., Oliveira C.C. 2005. Geologia e recursos minerais da Província Mineral de Alta Floresta. Relatório Integrado. Brasília, Serviço Geológico Brasileiro, CPRM, 164 p.

Tassinari C.C.G. \& Macambira M.J.B. 1999. Geochronological provinces of the Amazonian Craton. Episodes, 22(3):174-182.

Tassinari C.C.G. \& Macambira M.J.B. 2004. A evolução tectônica do Cráton Amazônico. In: Neto-Mantesso V., Bartorelli A., Carneiro C.D.R., Brito Neves B.B. (eds.) Geologia do continente Sul-Americano: evolução e obra de Fernando Flávio Marques de Almeida. Editora Beca, São Paulo, 647 p.

Thompson R.N. 1982. Magmatism of British Tertiary volcanic province. Scottish Journal of Geology, 18:49-107.

Watson E.B. \& Harrison T.M. 1983. Zircon saturation revisited: temperature and composition effects in a variety of crustal magma types. Earth and Planetary Science Letters, 64(2):295-304.

Wedepohl K.H. 1972. Barium, handbook of Geochemistry. SpringerVerlag, Berlin, p. 56-D-56-N.

Arquivo digital disponível on-line no site www.sbgeo.org.br 